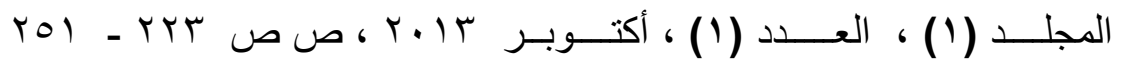

مستوى المهارات اللغوية لدى الأطفال المصابين بالثلل الدماغي المصحوب بإعاقة فكرية المدمجين في مدارس الدمج وأقرانهم غبر المدمجبن

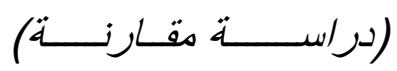

$$
\text { د / إعـدادي حسين آل هادي القحطاني }
$$




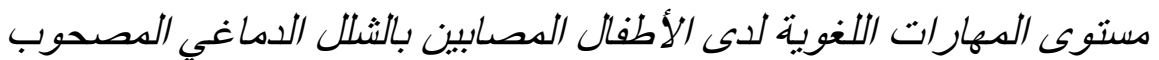

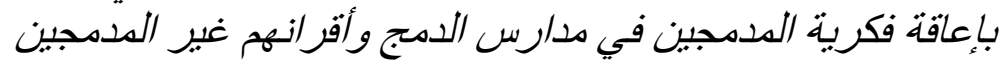

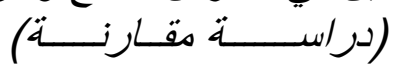

$$
\text { إعداد }
$$

د إد / هنادي حسين آل هادي القحطاني (*)

$$
\text { ملنــص }
$$

هدفت هذه الدراسة إلى التعرف على مستوى المهارات اللغوية لدى الأطفال المصابين

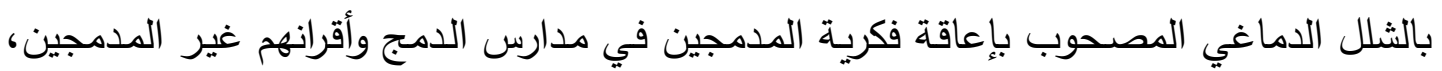
واستخدمت الباحثة المنهج الوصفي المقارن، وتكونت عينة الدراسة من التلميذات ذوات الثلل

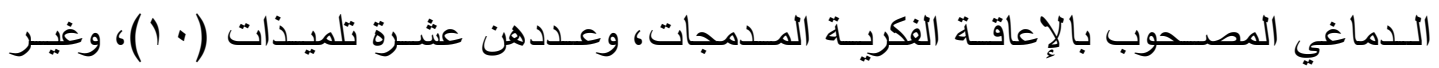

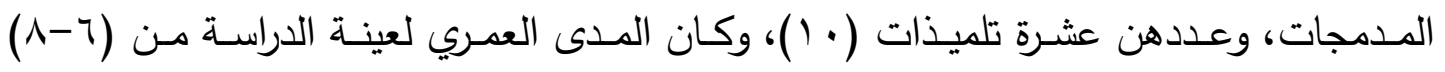

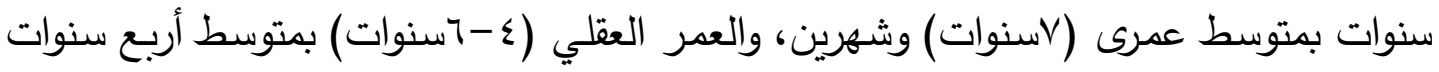
وستة شهور وقد استخدمت الباحثة مقياس ستانفورد بينيه للذكاء الصورة الخامسة المختصرة،

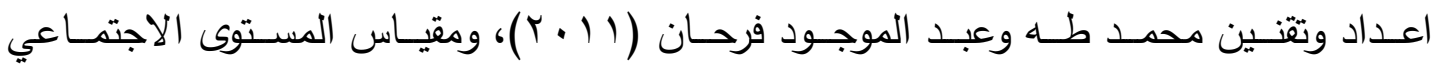
الاقتصادي للأسرة؛ بهدف ضبط العينة وتحقيق التجانس بين أفرادها، وكذلك مقياس المهارات

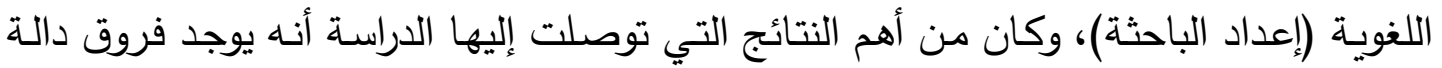

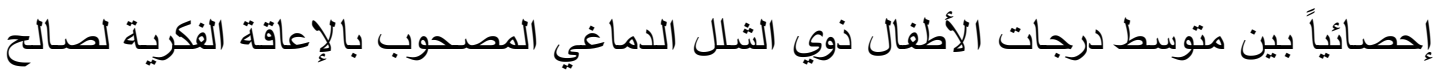

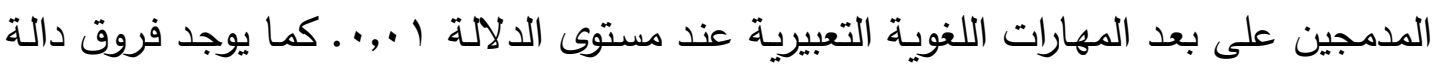

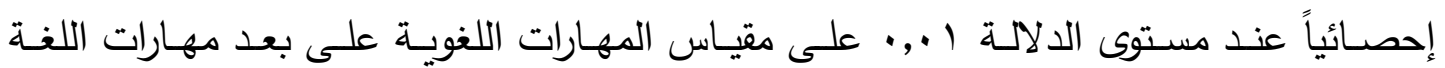
الاستقبالية لصالح المدمجين.

الكلمات المفتاحية: المهارات اللغوية، الثلل الدماغي، الإعاقة الفكرية، اللغة الاستقبالية، اللغة

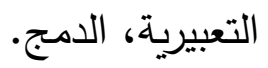


الإعاقات المتعددة هي تلك الإعاقات المتلازمة التي تسبب مشاكل تعليمية شديدة للطلاب بحيث لا يستطيعون معها أن يتلقون تعليمه ضمن برامج التربية الخاصة التي تم إعدادها لإعاقة واحدة، وتعد الإعاقات الثديدة والمتعددة إحدى القضايا المهمة التي لاقت رعاية صحية وتربويـة

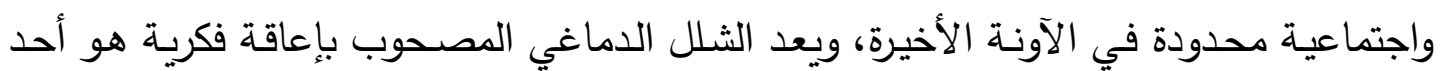
أشكال تلك الإعاقات المتعددة أو كما تسمى أحياناً المزدوجة. ويعرف التلاميذ ذوو الإعاقات الثـديدة والمتعددة بأنهم أولئك الأفراد الذين يعانون مـن مشكلات صحية، أو فكرية، أو حركية شديدة / متعددة مما يجعلهم بحاجة إلى تعديلات جوهريـة في المدرسـة، تستدعي تكييف المنهاج إلى الحد الذي يمكنهم من استيعاب محتواه. كما أنهم يحتاجون إلى توجيه وتعليم فردي كبير ؛ وذلك بهدف اكتساب المعرفة التي يدرسونها وتعميمها

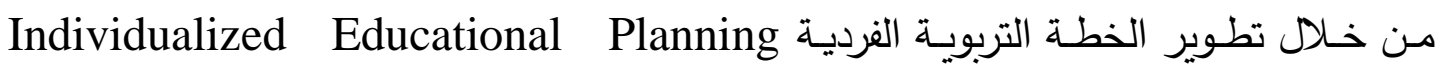

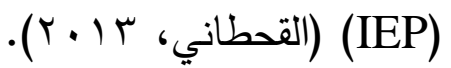
ويشير مفهوم الشـلل الدماغي إلى مظهر من مظاهر الإعاقات النمائيـة أو الاضطرابات

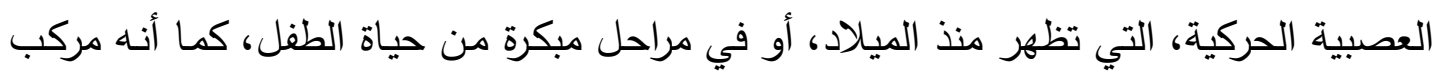
مـرتبط بـالتلف الـدماغي يظهر على شـل شـلل أو ضـعف، أو عـدم تـآزر حركي بصـري

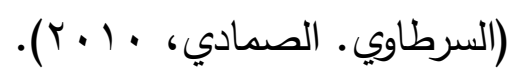

ويمكن القول إن الشلل الدماغي هو اضطراب نمائي ناجم عن خلل في الدماغ يظهر على شكل قصـور أو عجـز حركي مصـحوب باضـطرابات جسـية أو معرفيـة أو انفعاليـة. ونظـراً

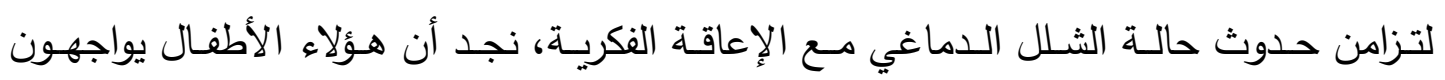
صعوبات شديدة في تعلم المهارات الأكاديمية، والمهارات اللغوية، ومهارات السلوك التكيفي، فهم بحاجـة دائمـة للمسـاعدة والـدعم في أداء المهـارات الاجتماعيـة، كمهـارات التفاعـل والتكيـف الاجتمـاعي والرغبـة في الإفصـاح عن حاجاتهم ورغباتهم وقدرتهم على التعامل مـع النقود، كما

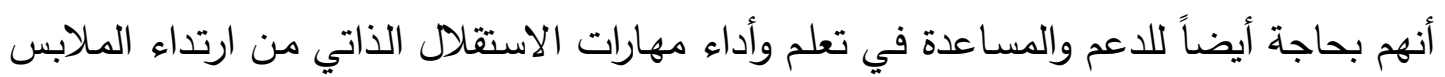

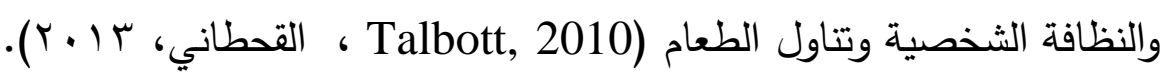
كــا يطلـق مصـطلح الشـلل الـدماغي أو الشـلل المخـي Cerebral Palsy على الاضطرابات النمائية أو العصبية التي تصيب الدماغ في مراحل مبكرة من حياة الطفل وخاصـة في فترة عدم اكتمال نمو القشرة الدماغية المسئولة عن الحركة، تتجم هذه الاضطرابات عن خلل 
أو تلف في الدماغ وتؤدي إلى عدد غير محدود من الأعراض والمشكلات الحركية والحسية

$$
\text { والعصبية (الخطيب، T . . T). }
$$

وعادة ما تكون هناك مشكلات وإعاقات مصاحبة للشلل الدماغي، لا تكون ناتجة عنـه

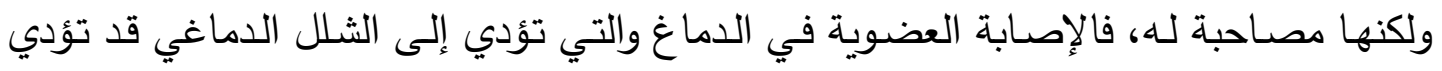

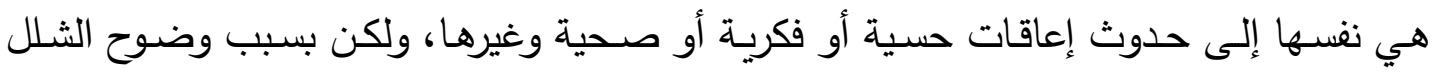

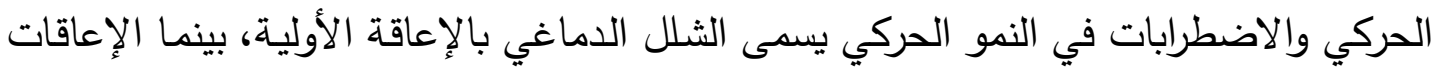

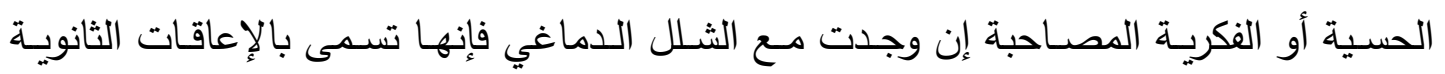

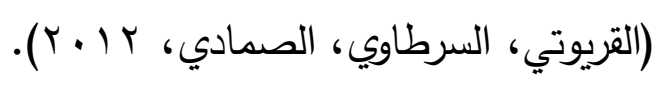

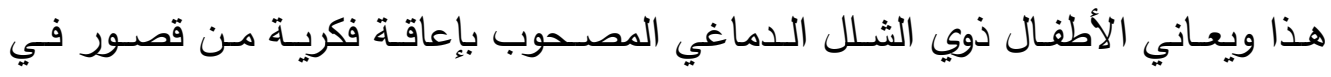
القدرات الفكرية والخبرات الحياتية، ومحدودية في مخزون استجاباتهم الحسية والحركية واللفظية،

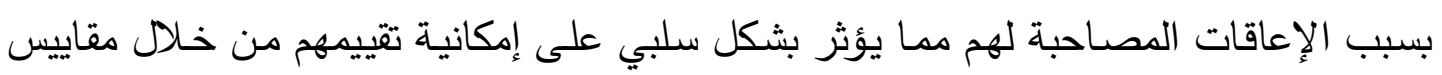

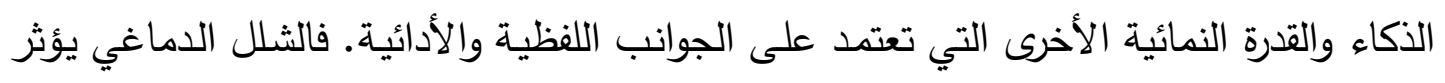

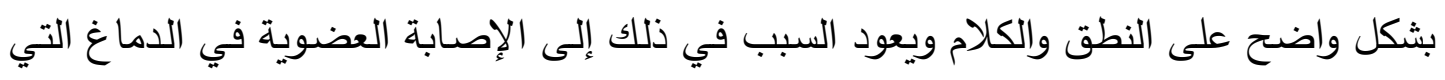

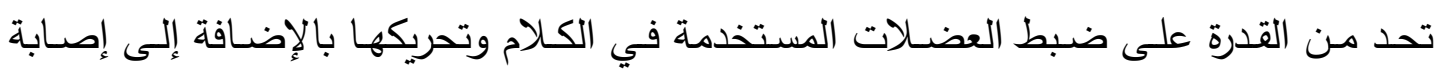

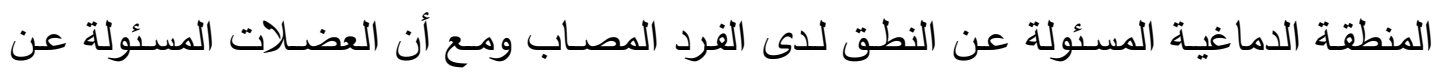

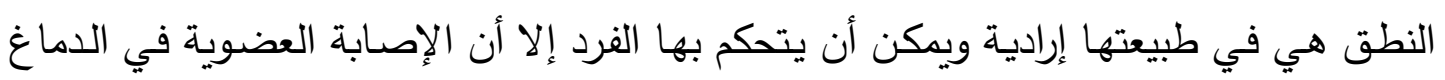

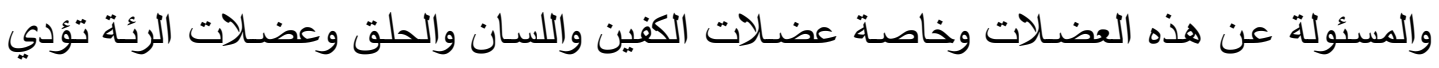

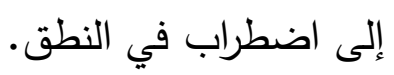

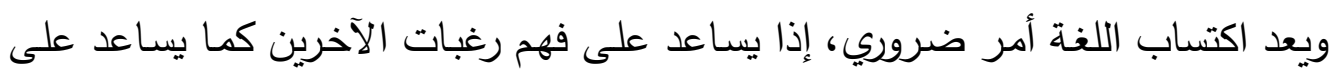

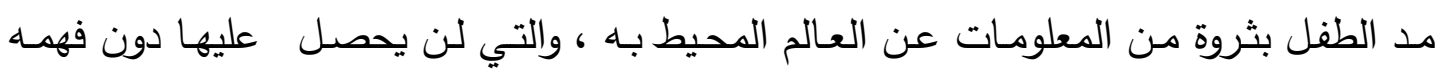

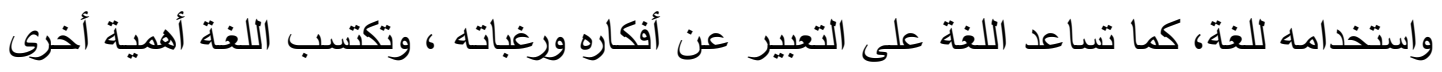

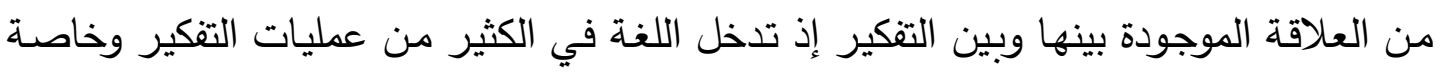

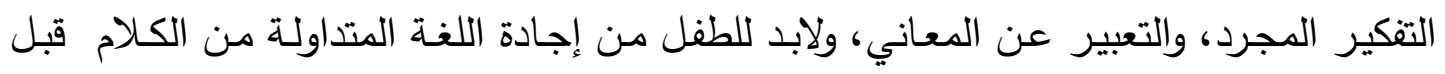

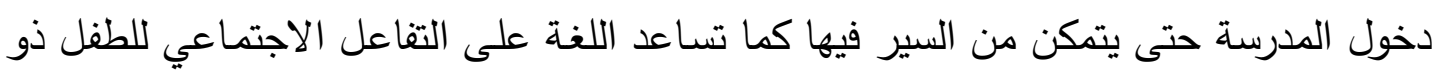
الإعاقة (السرطاوي. الصمادي، • • ب). وتظهر اللغـة بأشكال مختلفة كالمحادثة (الكـلام) والاستماع والقراءة والكتابـة، فـالكلام يمكن تشبيهه باللعب ليس فقط لكونه يسمح بأقصى درجة ممكنه من الإبداع، ولكن أيضًا لأنه 
يشكل وسيلة فعالة لا مثيل لها في التعبير، فالواقع أنه عن طريق الكلمة يظهر الطفل احتياجاته وحالة جسده ويفرغ توتراته الانفعالية والعاطفيـة ويخرج تجارِبهـ الحالية ويسترجع تجاربـه الماضية ويعبر عن شكواه الأولى وعن اقتتاعاته الساذَجة، إنها يكشف عن حقيقته للمحيطين بها، والكلمة هي عامل مؤثر جدًّا في التربية الفكريـة، فالكلام يحفز القدرة على الملاحظة والتحليل والمقارنـة والتصنيف والاستنتاج وتمثيل الماضي والتتبؤ بالمستقبل ويبلورها، والكلام التلقائي يتيح للإنسان التنفيس عن انفعالاته العاطفية، فهو صمام أمان وعلاج فعال للمرض النفسي، فالكلمة التلقائية

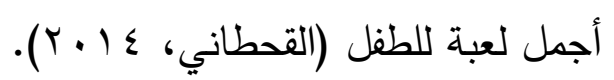
ويعتبر الاستماع أكثر أشكال اللغة ظهورا ثم الكلام ومن ثم تتراكم الخبرات لتصل إلى اللغة المكتوبة، فالخبرة اللغويـة المبكرة تشكل القاعدة المتينة للقراءة ومع تراكم الخبرة واستمرارها يتشكل لدى الطفل الألفـة في البنـاء اللغوي، كمـا تتوسـع دائرة مفرداتـه ويصبـح لديـه المعرفـة

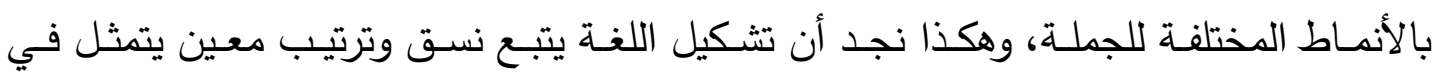

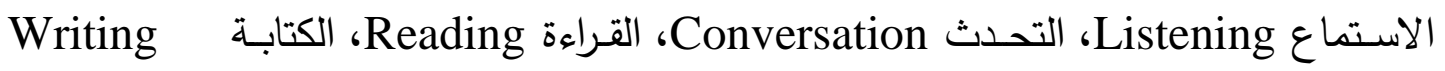

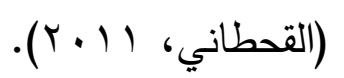

وتعتبر اللغـة في هذا الجانب مرتكزاً أساسياً لتتمية شتى المهارات الأخرى التي يكتسبها

الفرد في مختلف مراحل نمـوه، كمـا أن جميع المهارات اللغويـة متداخلـة ومتشـابكة وأي مهارة يكتسبها الفرد تساعده علي اكتساب المهارات الأخرى. وتتكون اللغة بصفة عامـة من مجموعة من المهارات وهي: الاستماع, والتحدث, والقراءة, والكتابة (الناشف, و99 ( ) .

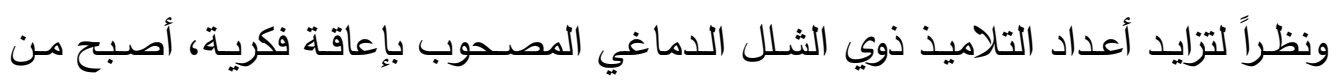

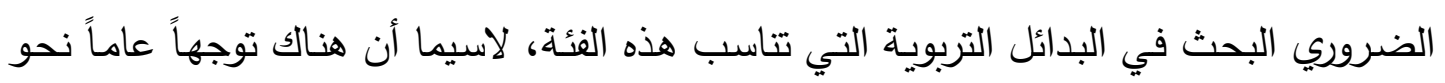
برامج الدمج لدى كلٍ من المهتمين والتربوين لرعاية هؤلاء التلاميذ من الناحية النفسية والتربويـة من خـلال دمجهم مـع أقرانهم العاديين في إطار بيئة أقرب إلى بيئة العاديين، وهذا من أهم أهداف التربية الخاصة. فجودة الحياة لدى ذوي الإعاقة عموما تقوم على أسـاس تمكينهم سواء كانوا أطفال أو بالغين أو راشدين من حقهم في الدمج الأسري والتعليمي ومن ثم المهني، وذلك لتحقيق احترام الفرد المعاق وحماية حقوقه الإنسانية ودعوته للالتزام بواجباته كمواطن شأنه في ذلك شأن أي مواطن يعيش في مجتمع متحضر يكفل لله الفرص المتكافئة ويحترم القيم الإنسانية والاجتماعية

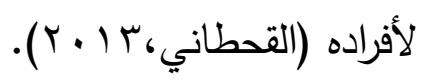


لذلك من الضروري وضع الطفل غير العادي مع الأطفال العاديين في الصف الدراسي في المدرسة العادية، مما يحقق مبدأ التطبيع نحو ممارسة الحياة العادية في أقل البيئات تقييداً.

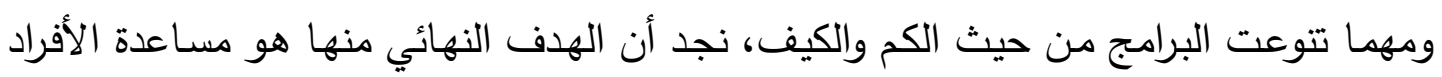

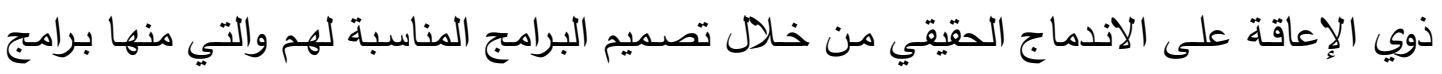
الدمج، بغرض تتمية المهارات اللغوية والاجتماعية والنفسية.

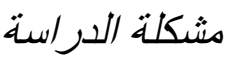

لاشكك أن وجود الطفل المعاق في فصـول الدمج يكسبه مهارات جديدة تجعله يتعلم

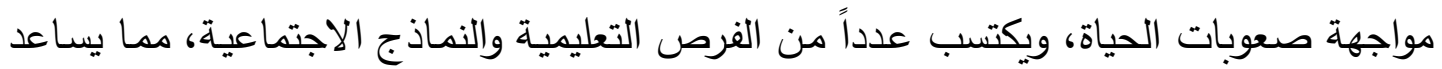

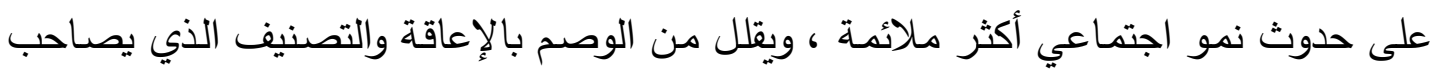

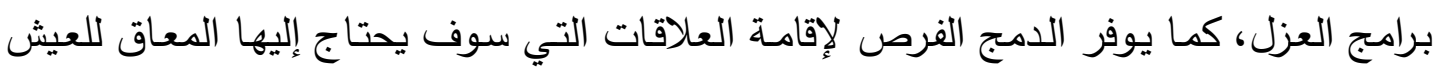
في الحياة والمشاركة في الأنشطة المجتمعية.

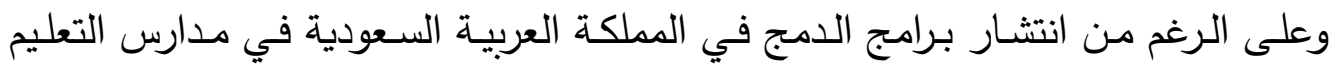

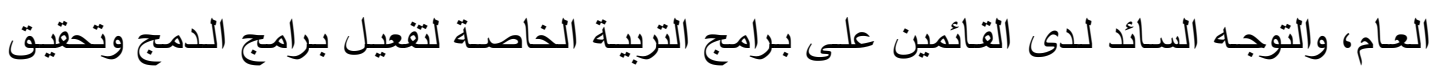

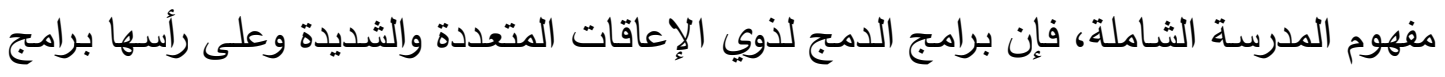

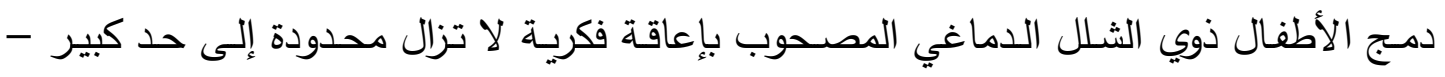

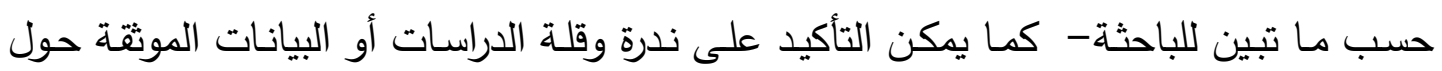

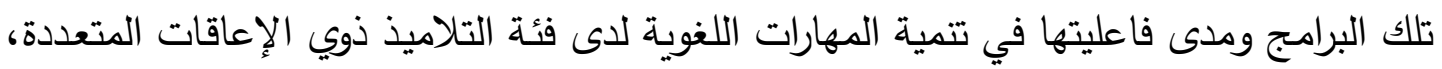
رغم أهمية هذه البرامج. ولذا فإن الدراسـة الحاليـة تسعى إلى بيـان فاعليـة برامج الدمج للتلاميذ ذوي الإعاقات

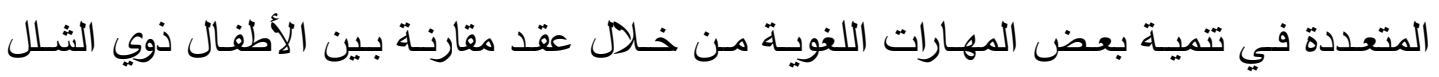

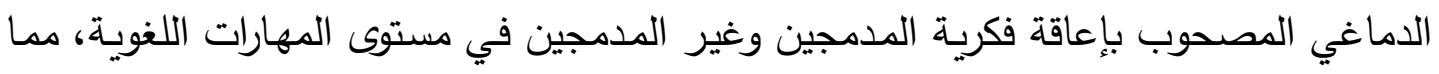

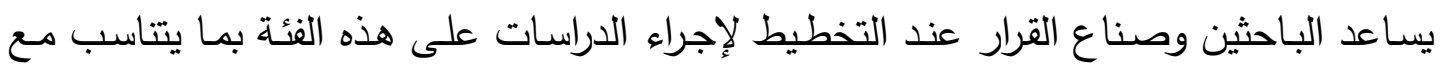

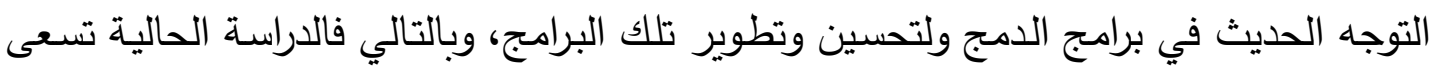

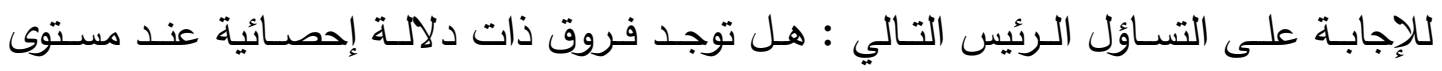

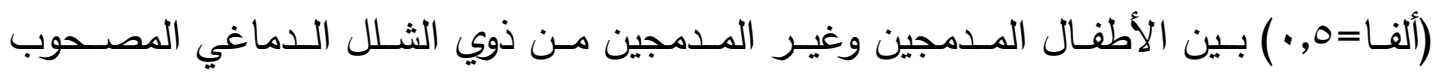

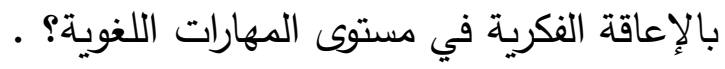


ا- معرفـة مدى فاعليـة برامج الدمج في تنميـة المهارات اللغويـة لدى الأطفال ذوي الشـلل الـدماغي المصـحوب بإعاقـة فكريـة والتـي تتمثل في مهـارات اللغــة التعبيريـة واللغــة الاستقبالية.

( ) إعداد مقيـاس للمهارات اللغويـة لدى الأطفـال ذوي الشـلل الـماغي المصـحوب بإعاقـة فكربة.

ץ) تقديم خدمة إرشادية توجيهية للقائمين على التربية الخاصة بالمملكة العربية السعودية. أهمبية الدراسة ما زال اهتمام المملكة العربية السعودية بذوي الإعاقة موصولاً بتوفير كافة سبل التربية والتعليم لهم من خلال فتح البرامج التربوية المتعددة لمختلف فئات التربية الخاصة، ومن ضمنهم فئة ذوي الشلل الدماغي المصحوب بإعاقة فكريـة، غير أن هذه الفئة من فئات التربية الخاصـة

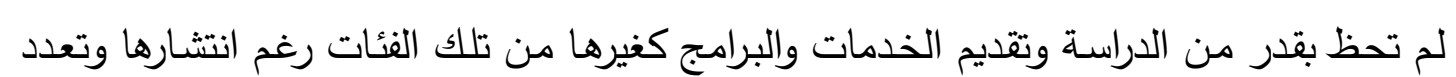
مظاهرها، ولذلك تكتسب الدراسة الحالية أهمية نظرية وأخرى تطبيقية.

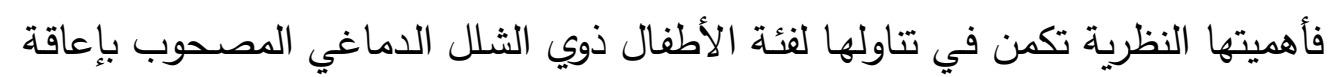
فكرية باعتبارهم إحدى فئات الإعاقات المتعددة، أما أهميتها التطبيقية فتتجلى في كونها محاولة علمية جادة للكشف عن فعالية برامج الدمج في تنمية المهارات للغويـة لدى التلاميذ ذوي الثلل الدماغي المصحوب بإعاقة فكريـة الإعاقات المتعددة، وكذلك تعد دراسـة أصيلة في الميدان في حدود علم الباحثة- ومن هنا جاءت أهمية هذه الدراسة. المصطلحـــات تتبنى الدراسة الحالية المصطلحات التالية : الأطفال المصابين بالثلل الدماغي المصحوب بإعاقة فكرية Cerebral Palsy Accompanied by Intellectual Disability وتعرفهم الباحثة على أنهم: هؤلاء الأطفال المصابون باضطرابات نمائية أو عصبية في الدماغ خـلال مراحل مبكرة من حياتهم وخاصـة في فترة عدم اكتمال نمو القشرة الدماغيـة المسئولة عن الحركة، تتجم هذه الاضطرابات عن خلل أو تلف في الدماغ وتؤدي إلى عدد غير محدود من الأعراض والمشكلات الحركية والحسية والعصبية. وإجرائياً: هم التلاميذ الذين تم 
تشخيصهم طبياً وتربوياً بأنهم يعانون من شلل دماغي مصحوب بإعاقة فكرية وهم قادرون على ، ونى التعلم وتتراوح نسب ذكائهم من •O إلى •V درجة على مقياس ستافورد بينيه للذكاء.

\section{Language Skills}

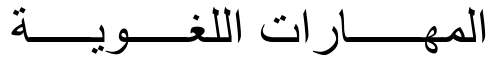

وتعرفها الباحثة على أنها مجمل الأنشطة التي يمارس الفرد بعضها للاستماع والتلقي

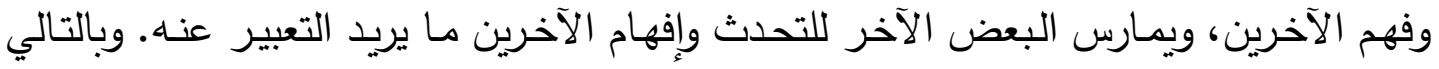

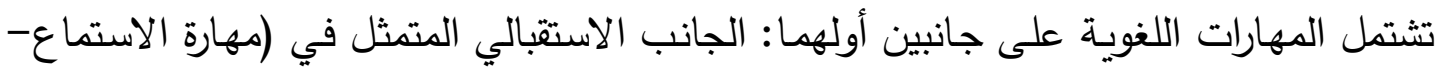

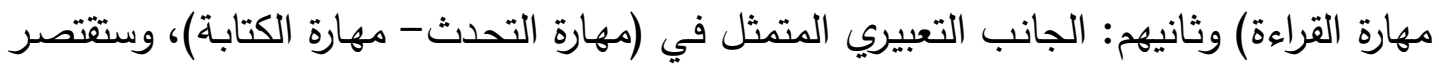

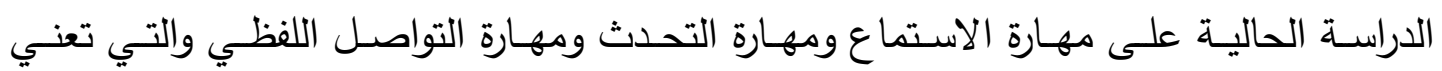
التتسيق بين مهارتي الاستماع والتحدث بهدف تتمية قدرة الطفل ذو الثلل الدماغي المصدوب

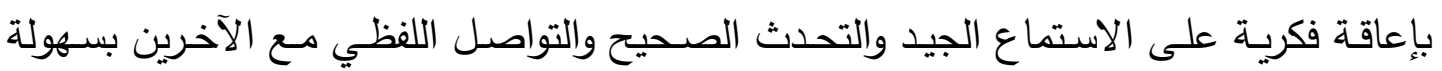
وإتقان. وإجرائياً : الدرجة التي يحصل عليها المفحوص على مقياس المهارات اللغويـة (إعداد

\section{Inclusion}

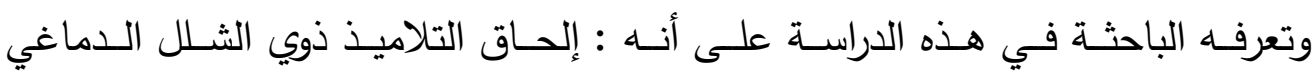

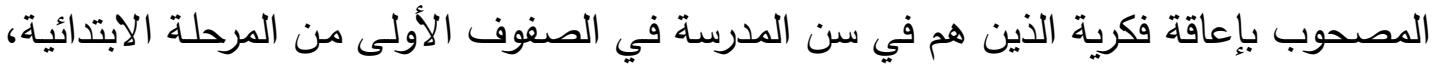

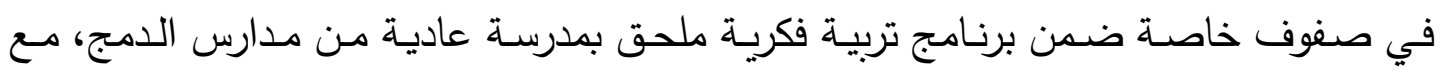
استمرار تقديم الدعم لهم من خلال معلمات الصف وغرف فرنه الهصادر والتعليم العام.

$$
\text { إطار نظري ودراسات سابقة }
$$

اتجهت الأنظار في الآونة الأخيرة نحو أهمية برامج دمج ذوي الإعاقات المختلفة، والتي

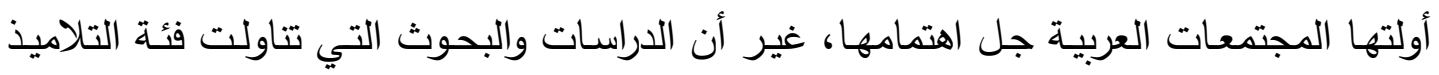
ذوي الإعاقات المتعددة مازال فيها ندرة؛ بالرغم من أن نتائج كثير من الدراسات تثير إلى نهات نهاح فكرة الدمج لاى التلاميذ ذوي الاحتياجات الخاصـة، وكذلك رفع كفاءتهم الاجتماعية والنفسية والمعرفية وكذلك سلوكهم التكيفي. 
حيث أن الأطفال ذوو الإعاقـات الثـديدة والإعاقـات المتعددة يعانون مـن قصور في القدرات العقلية والخبرات الحياتية، ومحدودية في مخزون استجاباتهم الحسية والحركية واللفظية، بسبب الإعاقات المصساحبة للإعاقة العقلية، مدا يؤثر بشكل سلبي على إمكانيـة تقييمهم من خلال مقاييس الذكاء والقدرات النمائية الأخرى، التي تعتمد على الجوانب اللفظية والأدائية. فالإعاقـة العقليـة مـن الإعاقـات الرئيسـة، التي تكـون متزامنـة مــع كثير مـن الإعاقـات المتوسطة والثديدة، فقد أكد كثرر من الباحثين أن ذوي الإعاقات المتوسطة والثديدة يعانون من قصور حاد في قدراتهم اللفظيـة والمعرفيـة، ومهاراتهم السلوكية والاجتماعية، كمـا يظهر لديهم قصـور واضـح في الذاكرة، والتصـيف والاسـتدلال والتقيـيم، حيث يعـاني حوالي ستين بالمئسة ( • ٪\%) من الأفراد ذوي الإعاقة العقلية من الشلل الدماغي، ويشير مفهوم الشلل الدماغي إلى

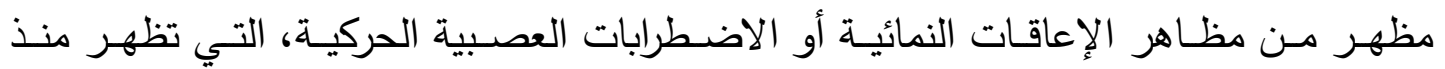
الميلاد، أو في مراحل مبكرة من حياة الطفل، كما أنه مركب مرتبط بالتلف الدماغي يظهر على شكل شلل أو ضعف، أو عدم تآزر حركي بصري (Talbott 2010). ويمكن القول إن الشلل الدماغي هو اضطراب نمائي ناجم عن خلل في الدماغ يظهر على شكل قصور أو عجز حركي مصحوب باضطرابات جسمية أو معرفية أو انفعالية. ونظراً لتزامن حدوث حالـة الثـلل الـدماغي مـع الإعاقـة العقليـة، نجـــ أن هـؤلاء الأطفـال يواجهـون صعوبات شديدة في تعلم المهارات الأكاديمية، والمهارات اللغوية، ومهارات السلوك التكيفي، فهم بحاجـة دائمـة للمسـاعدة والـدعم في أداء المهـارات الاجتماعيـة، كمهـارات التفاعـل والتكيـف الاجتماعي والرغبـة في الإفصـاح عن حاجاتهم ورغباتهم وقدرتهم على التعامل مـع النقود، كما أنهم بحاجة أيضاً للدعم والمساعدة في تعلم وأداء مهارات الاستقلال الذاتي من ارتداء الملابس والنظافة الشخصية وتتاول الطعام. فالصعوبات الشديدة التي يواجهها هؤلاء الأطفال في مهارات السلوك التكيفي تحد من قدرتهم على الاستقلالية والنمو السليم• (القحطاني، با ـ ז. . 2010,

(Talbott

ويشكل التواصل غير اللفظي الجانب الأكبر مـن عمليـة التواصل، حيث إنـه عمليـة ديناميكية يشترك فيها العقل والجسم، و تظهر من خلالها معاني رمزيـة لسلوكيات الفرد الذاتية، تضـم أشكالاً متتوعـة كالإشـارات اليدويـة أو الإيمـاءات الجسمية أو التعبيرات الوجهيـة. (خيـال، 


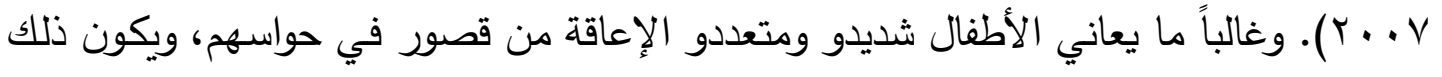

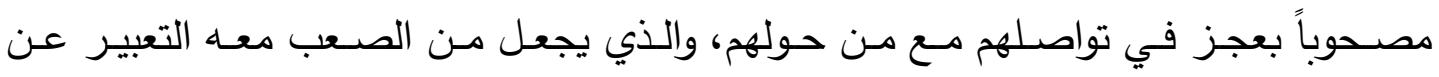

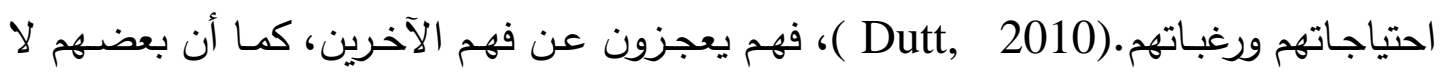
يستطيع أن يتحدث، أو حتى بالإيماء بشكل مفهوم، وقد لا يستجيب في حالة وجود محاولـة

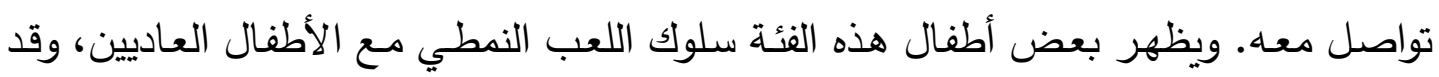

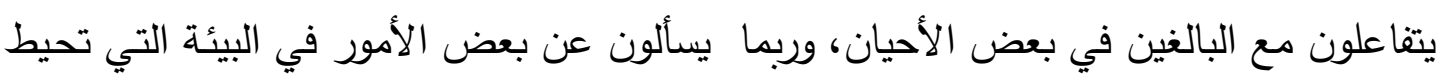

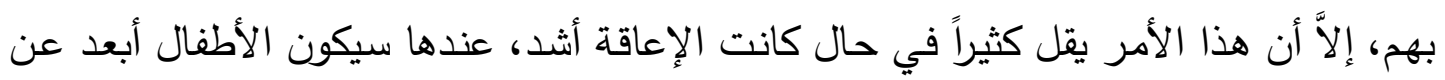

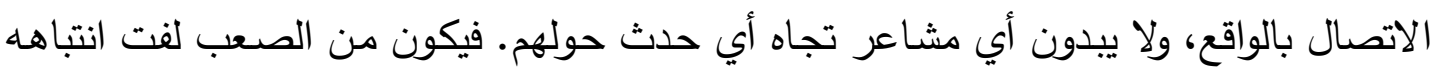
أو استفزازه أو ملاحظة أي ردة فعل منه.(Heward, 2009)

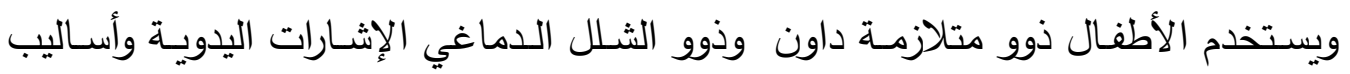

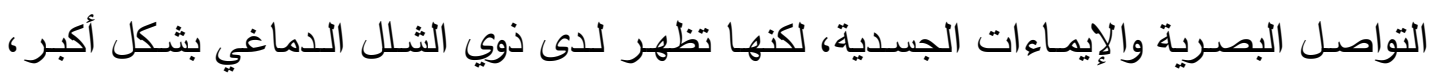

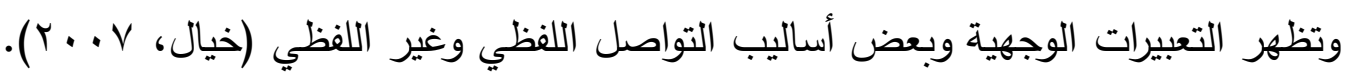

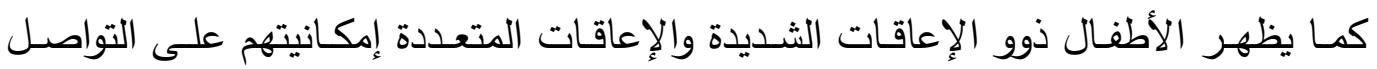

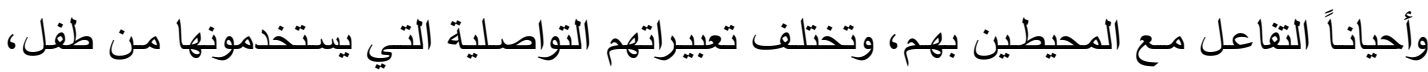
لآخر وبحسب فهم الآخرين لشكل هذا التواصل. فبعض الأطفال يستخدمون التواصل غير

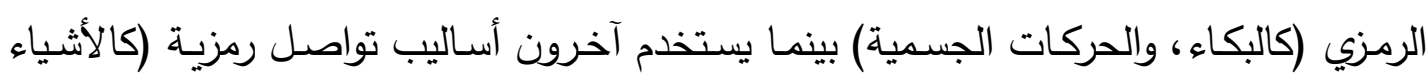

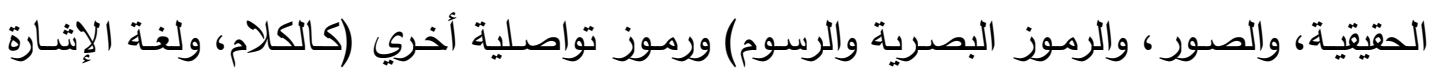
الدائمة) (Reeder, 2002). ويمكن القـول أن التلاميذ ذوو الإعاقـة الفكريـة والإعاقـات المصـاحبة يعـانون مـن

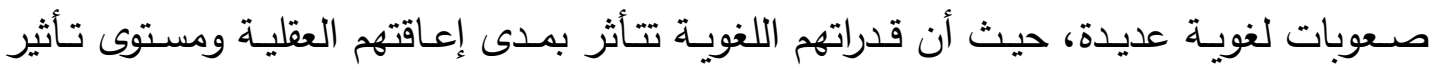
الإعاقة المصاحبة، ومن أهم هذه الصعوبات اللغوية مايلي: 1- - ن نطق الكلمة، أو الكلمتين في مدة أطول من المعتاد.

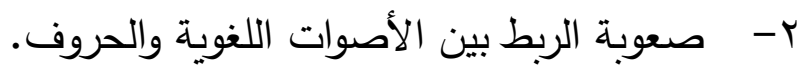
ب- بـ - نقص الثروة اللغوية. ع- ضعف القدرة على تذكر المفردات اللغوية الجديدة. 
0- - قصور في القدرة على استخدام اللغة الرمزية. 7- اتصال الأفكار بالمحسوسات.

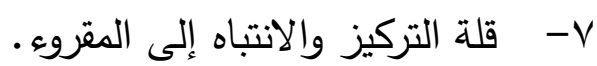

- م- صعوبة الربط بين المقروء والمفهوم، أو المدلول.

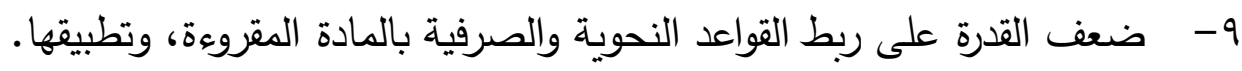

• 1- ضعف استدعاء المحتوى المقروء من الذاكرة.

11 إساءة الفهم للتعليمات والتعبيرات اللغوية.

r ا - ضعف القدرة على تحليل الكلمات إلى الحروف المكونة لها.

rا - ضعف الذاكرة البصرية، خاصة الكلمات الجديدة.

ـ ا - نقص القدرة على التجريد والتمييز.

10 - نقص الدافعية والإثارة، لتعلم المهارات اللغوية، لاسيما القراءة والكتابة.

17 - نقص القدرة على الفهم والاحتفاظ بالمقروء، أو المسموع.

V V - صعوبة تتسيق حركة الجسم، خصوصًا اليد أثناء الكتابة.

1 ا - نقص القدرة على التفاعل والتواصل اللغوية في مواقف الاتصال.

9 1 - صعوبة تكوين الجمل على المستوى الثفوي.

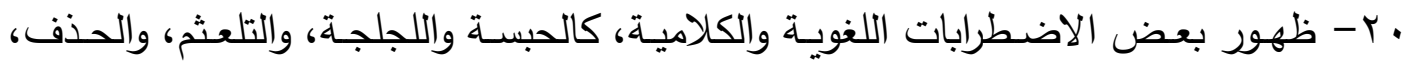

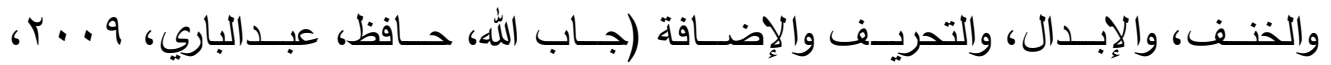

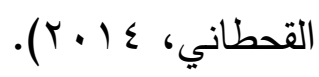

وقد دللت نتائج البحوث والدراسـات، أن التلاميذ ذوي الإعاقة الفكريـة أبطأ في نموهم

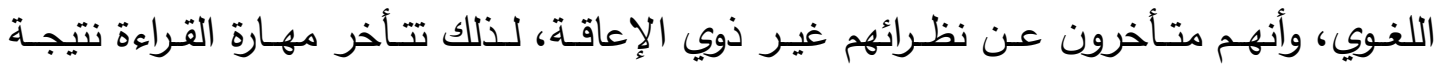

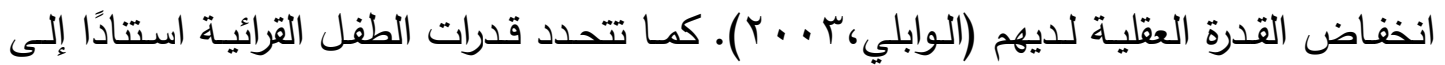

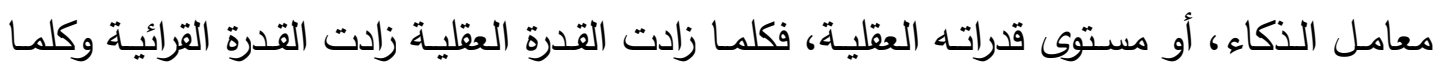
انخفضت القدرة العقلية انخفضت القدرة القرائيـة فقد يتمكن ذوو الإعاقـة الفكريـة البسيطة من

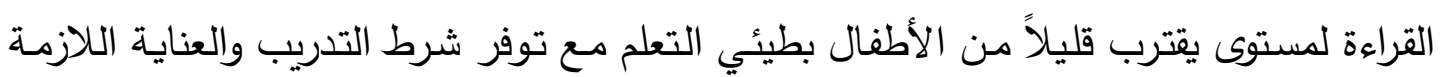

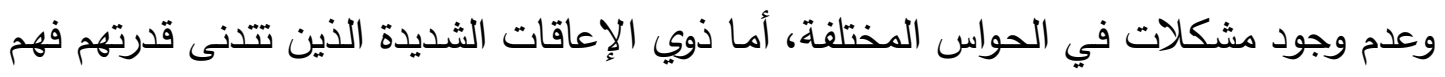
لا يتقنون مهارات القراءة لعدم وصولهم إلى الاستعداد القرائي المناسب، بالإضـافة إلى وجود 
Conners. Frances. Rosenquist, Sligh, . 1914، مشكلات أخرى (أبو العزايم Bos, Nakken, Nicolay \& , Allison, Atwell, Julie, \& Kiser 20062007 .(Van, Houten ومما هو جدير بالذكر أن الطفل ذي الإعاقة الفكريـة يعاني من صعوبات أكثر في تعلم

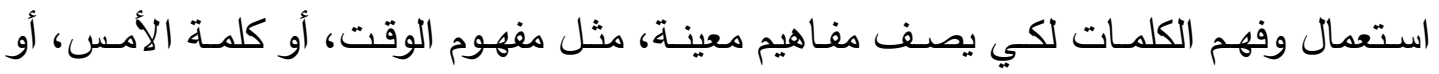

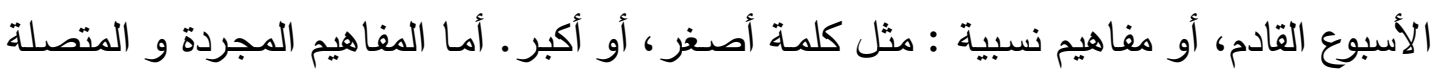

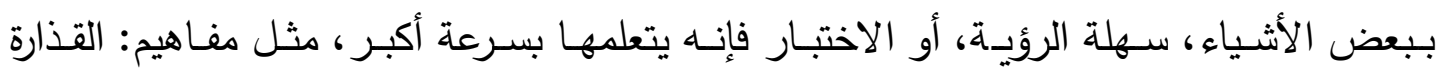

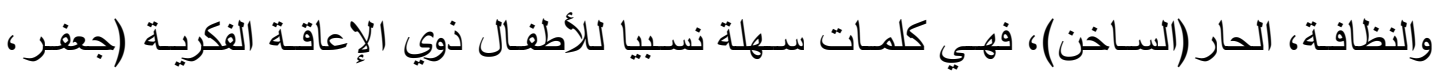
$\cdot(r+$. وفي ضوه جميع مـا سبق فقد أشـارت كثير من الدراسـات إلى أهمية برامج الدمج في

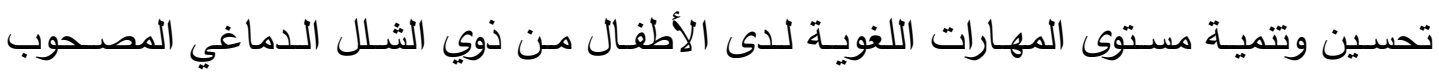

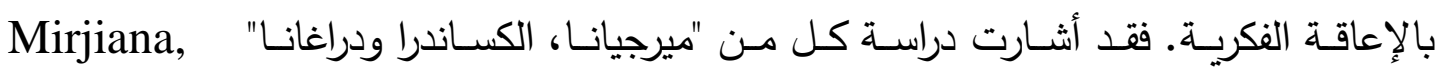
ذأل Aleksandra \& Dragana

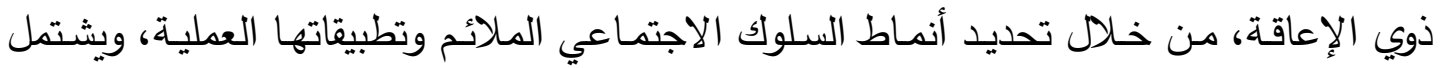

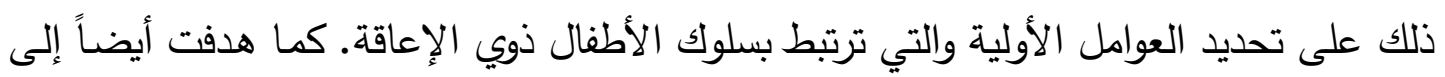

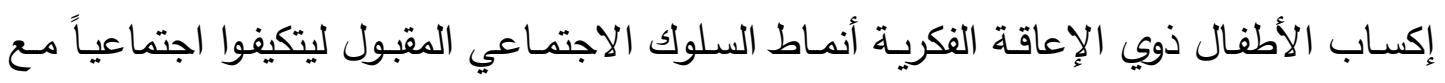

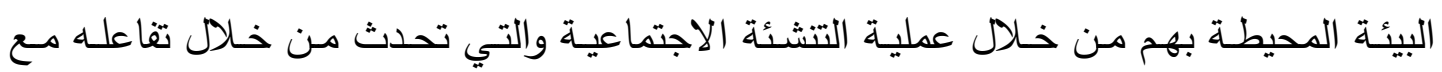
البيئة،، وأظهرت نتائج الدراسة أن هناك ارتباطاً وثيقاً بين السلوكيات المقبولة اجتماعياً ودرجة

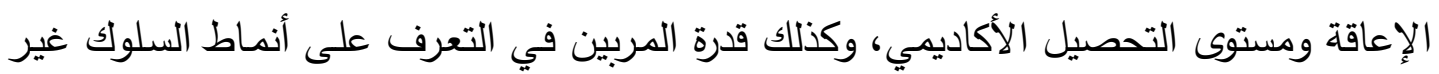

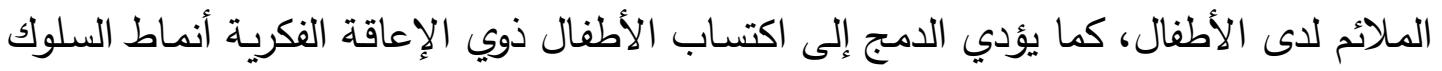
المقبول من خلال القدوة وتقليدهم للآباء والمعلمين والأقران.

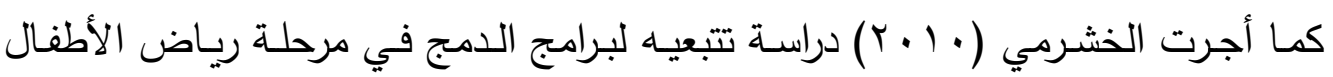

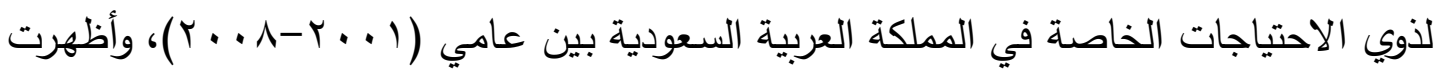

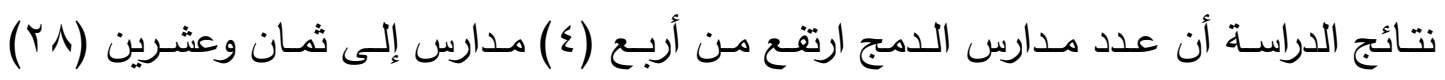

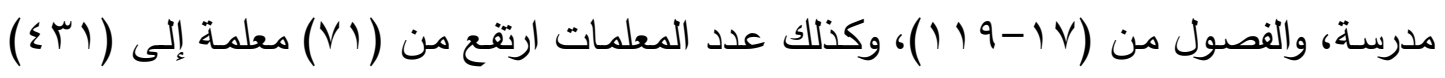

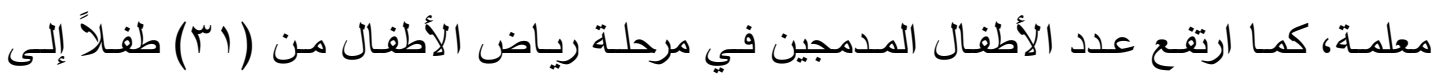




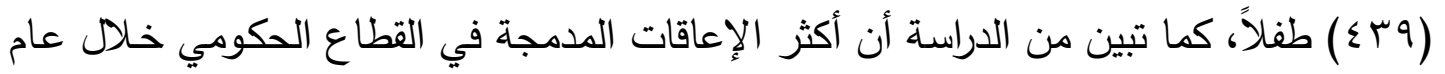

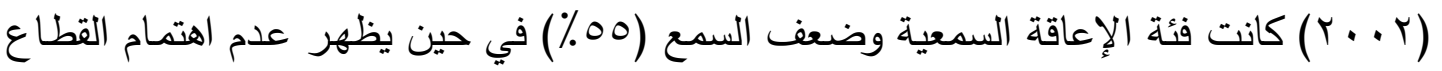

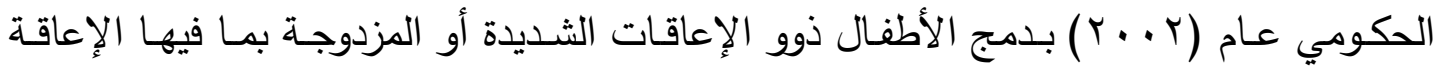

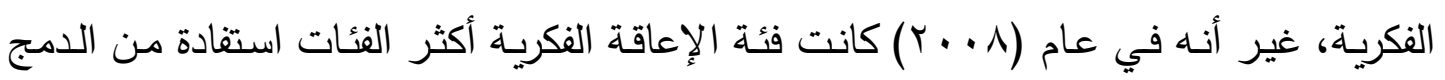

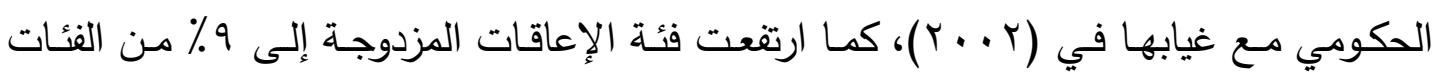

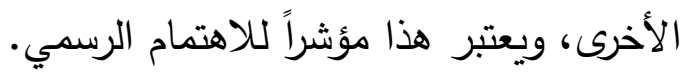

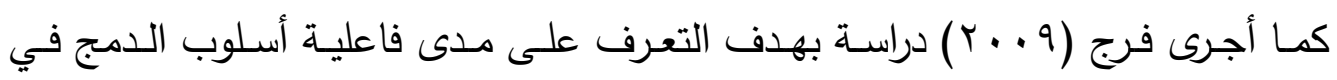

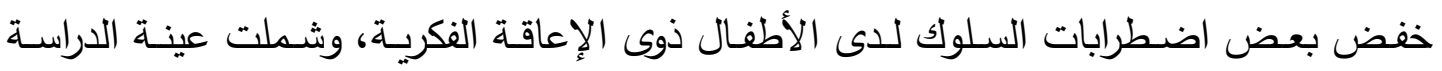

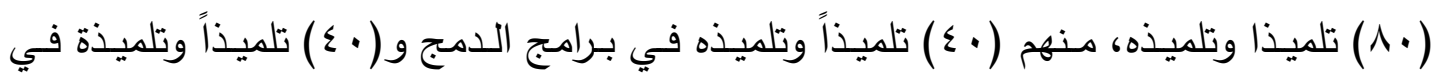

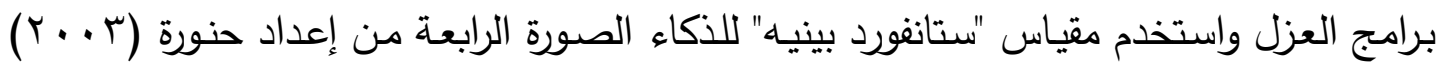
ومقياس السلوك التكيفي من إعداد فاروق صادق (910 (1).

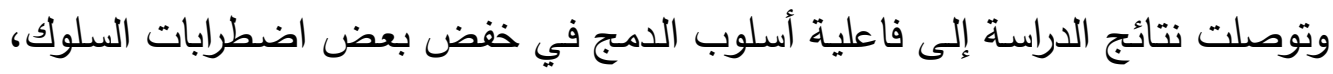

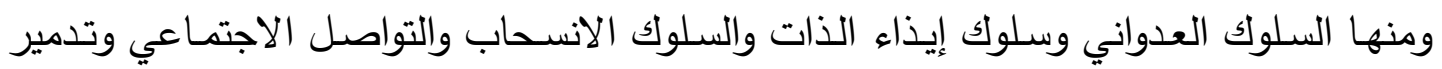

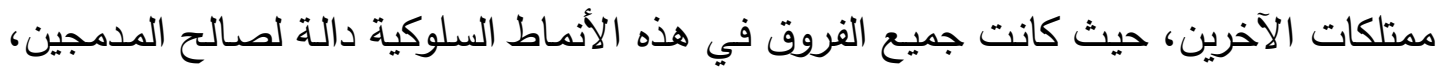

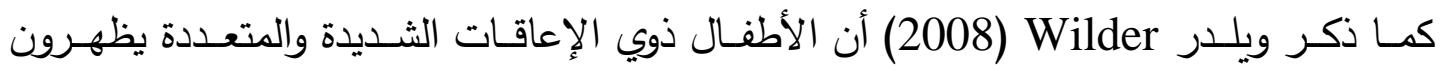

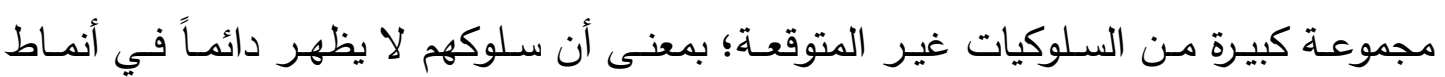

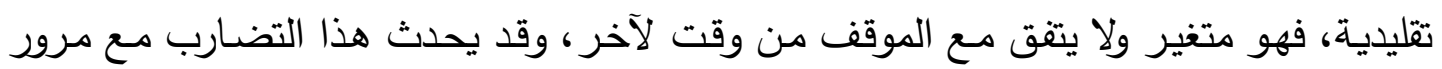

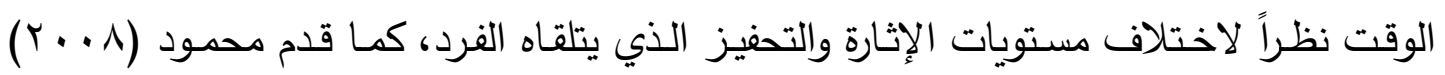

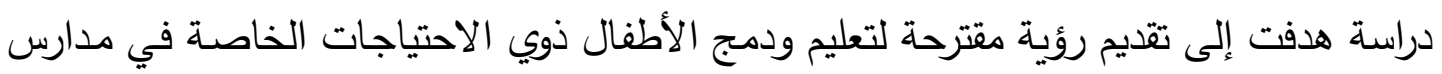

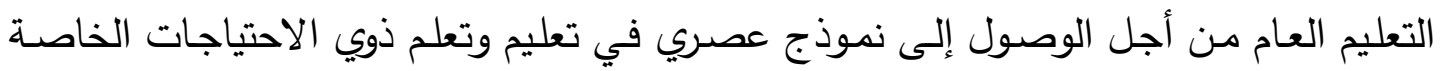

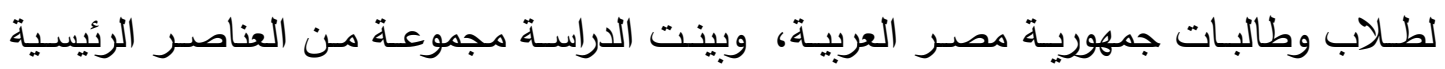

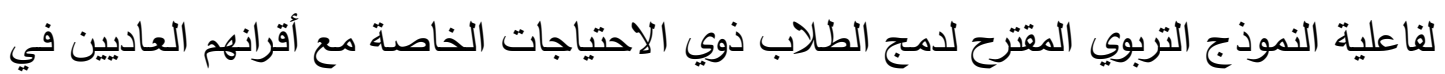
مدارس التعليم العام، (كتوفير قيادات قوية، وإيجاد خطة منظمة، وتوفير وسائل دعم، واستخدام

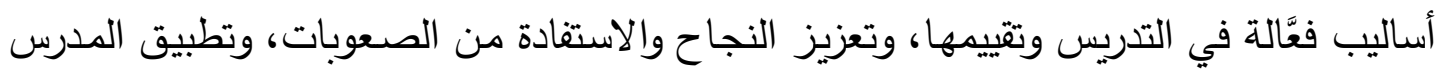
لإجراءات التغيير ، وغيرها).

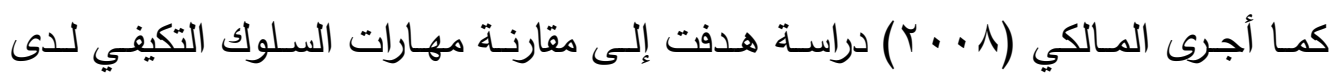

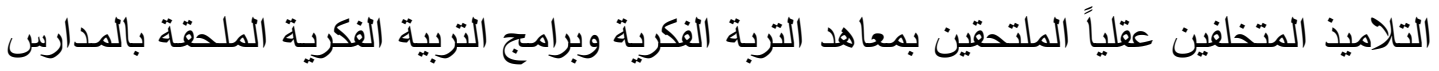


العادية، وقد تكونت عينة الدراسة من (• (7) تلميذاً من ذوي التخلف العقلي البسيط والذين تتراوح

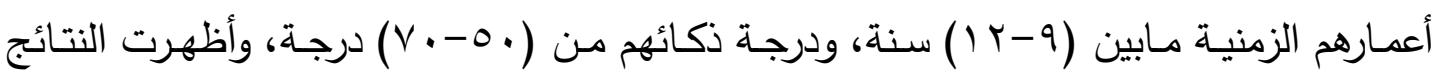
وجود فروق ذات دلالة إحصائية بين متوسط درجات تلاميذ المعهد ومتوسط تلاميذ برامج التربية

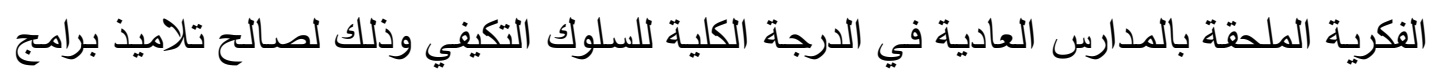
التربية الفكرية الملحقة بالمدارس العادية. كما أنه توجد فروق ذات دلالة إحصائية بين متوسطات درجات تلاميذ المعهذ ومتوسطات باتهات

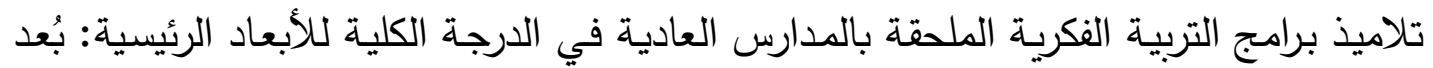

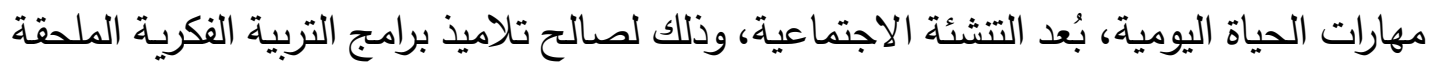
بالمدارس العادية، وقد أجرى ستانكو Stanco (2008) دراسة هدفت إلى التحقق من فاعلية برنامج تدريب مهني في مدارس الدمج على المهارات الاجتماعية والميل نشاط الزائد من خلال

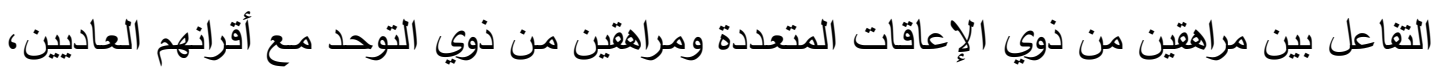

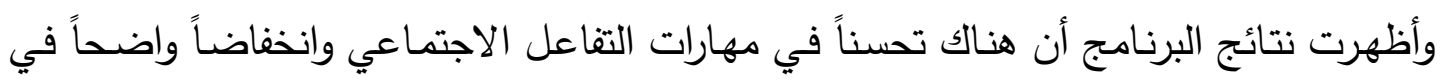
سلوك النشاط الزائد، كما زاد السلوك الهادف مـع اختفاء سلوك الانسحاب الاجتماعي لصالح المجموعة المدمجة التي طبقت البرنامج التدريبي. وفي دراسة البهاص (Y. P P. التي هدفت إلى الكثف عن مدى فعالية برنامج تدريبي

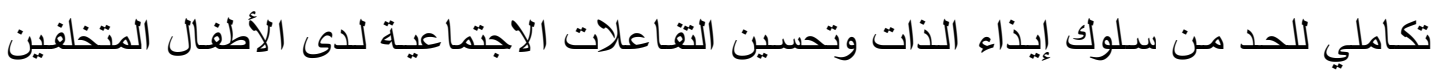

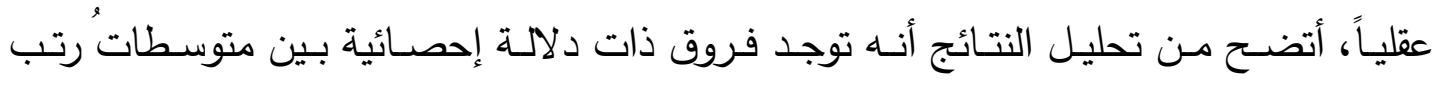

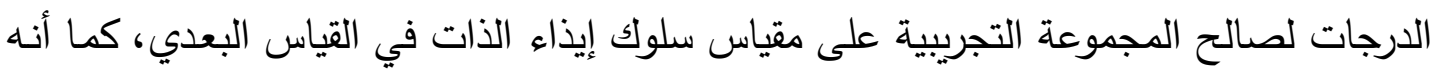

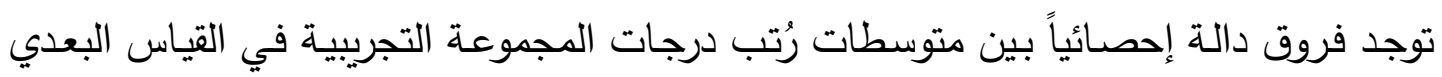
على مقياس التفاعلات الاجتماعية.

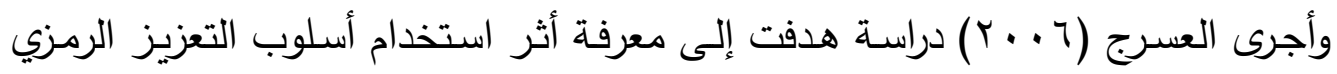

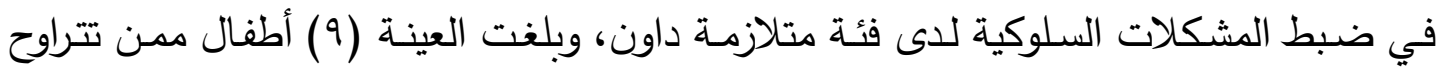

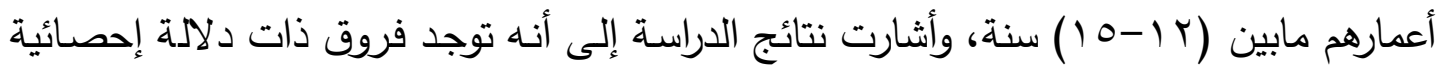

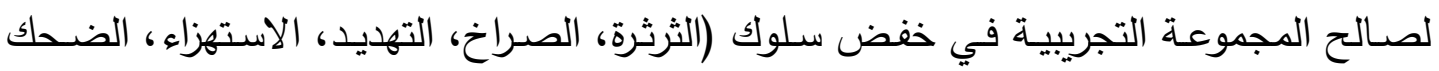
بدون سبب، الارتماء على الأرض). 


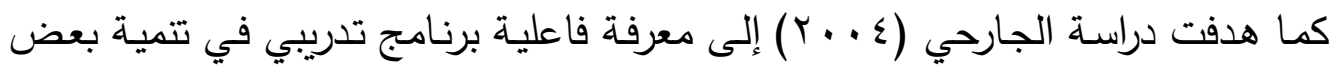

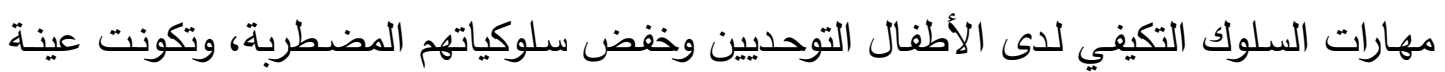

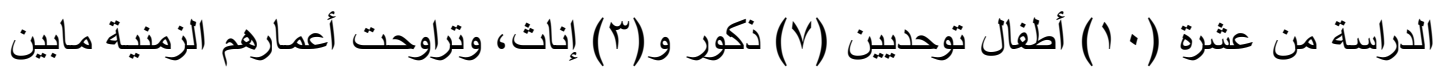

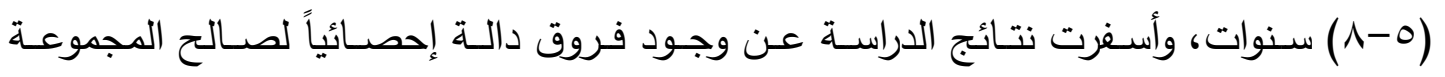

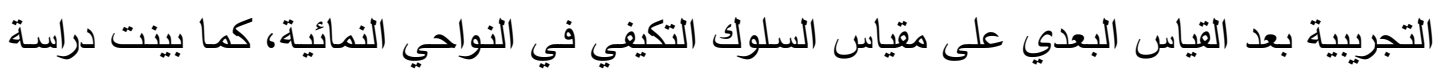

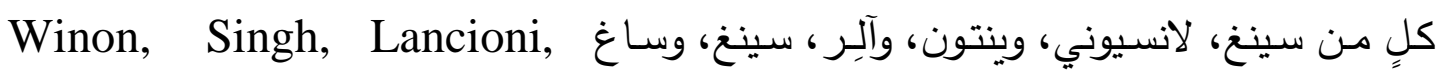
Wahler, Singh, Sage الرفرفة، الضحك، والحركات الجسمية التي تدل على الفرح) ظهر بشكل واضح لانى الأطفال

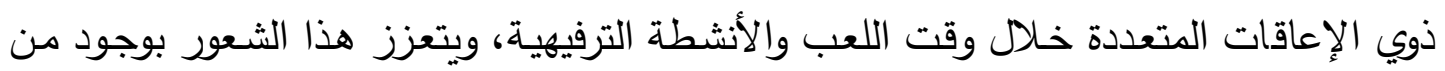

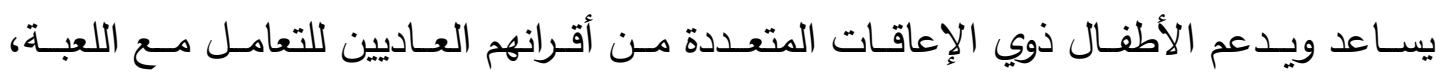

ومشاركتهم بالأنشطة التي يفضلونها، كتقديم الغذاء للعبة، والعناية بها، وتمشيطها وتنظيفها. ونظراً للقصور الواضح في الجوانب المعرفية لدى التلاميذ ذوي الإعاقات المتعددة، فإنـه

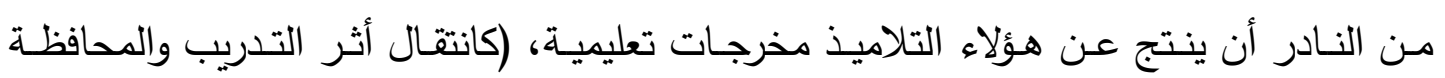

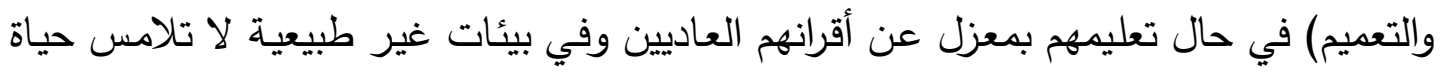

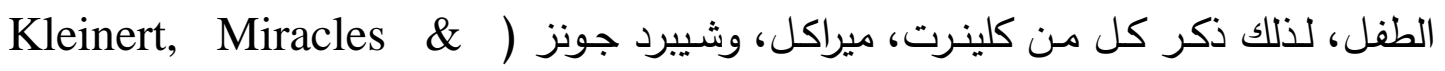

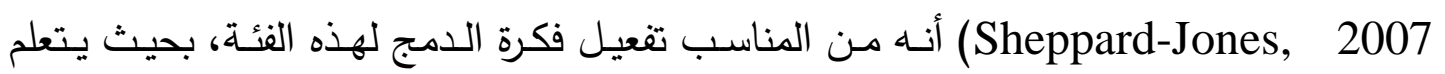

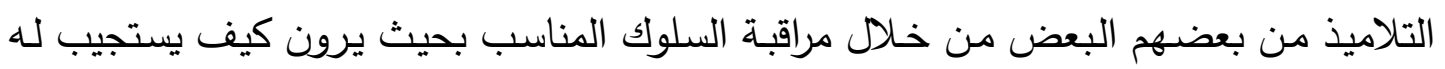

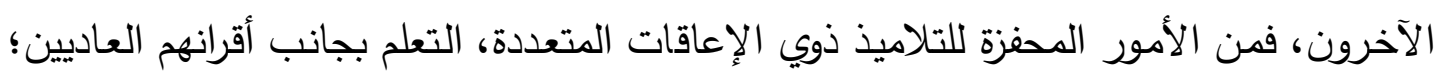

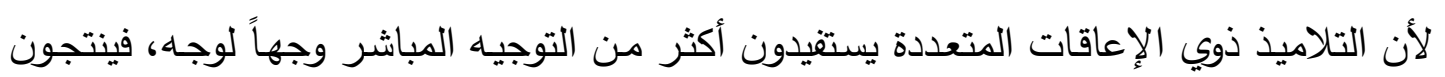

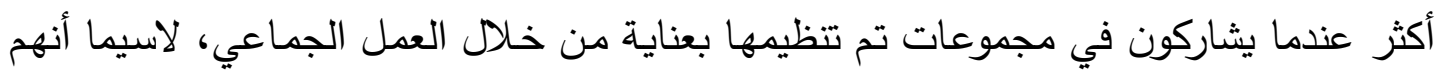

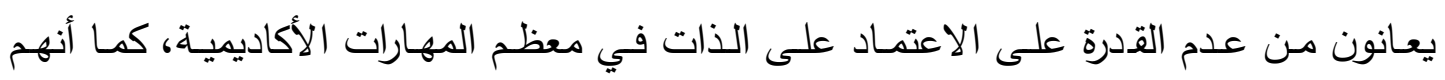

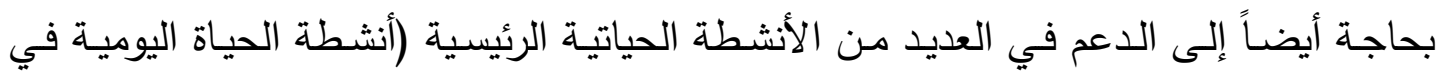
المنزل، قضاء أوقات الفراغ، المشاركة الاجتماعية، العمل، وغيرها).

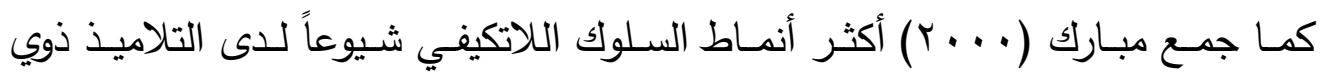
الإعاقة الفكرية في مدارس التربية الفكرية، وهي (التدمير والإتلاف والتخريب، الاعتداء والمكايد

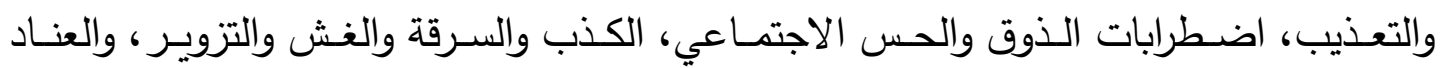

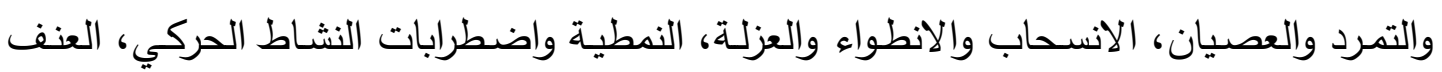




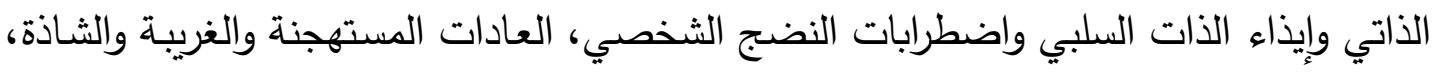

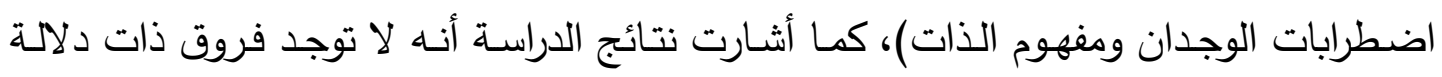
إحصائية بين الذكور والإناث في سلوك الكذب والسرقة والغش والتزوير واضطرابات الوجدان التهان التهان ومفهوم الذات.

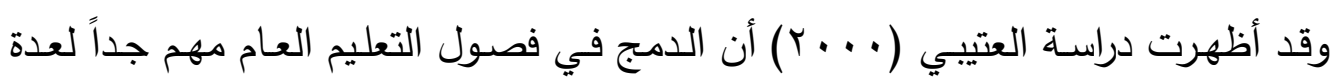

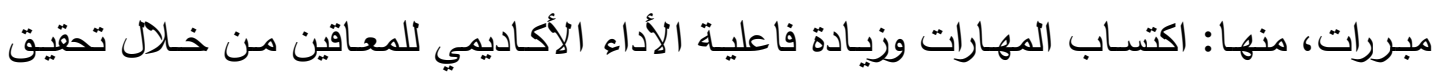
أهداف الخطة التربويـة الفردية (IEP) في المدرسـة العادية، بحيث يكونوا أكثر حماساً وتحفيزاً

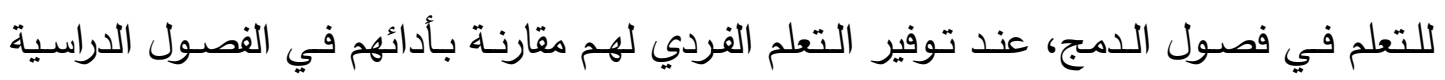

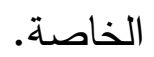

ومن المرجح أن تتشأ علاقات صداقة بين التلاميذ من ذوي الإعاقة والتلاميذ العاديين،

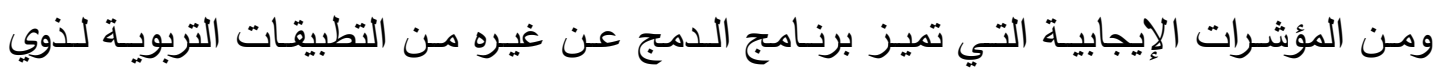
الإعاقات الثديدة، أن هذه الايجابيات تشتمل على قضاء اليوم الدراسي بجانب التباتب التلاميذ العاديين

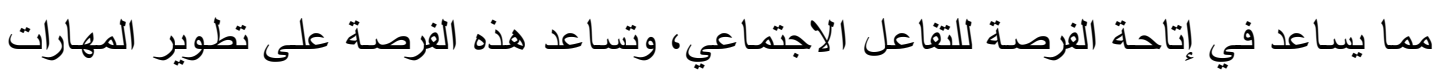

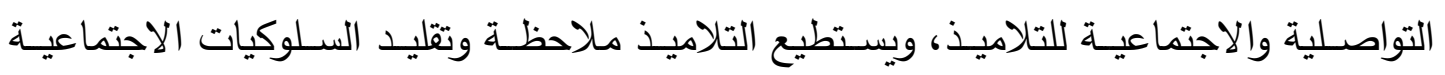

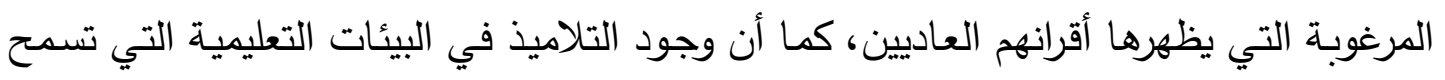

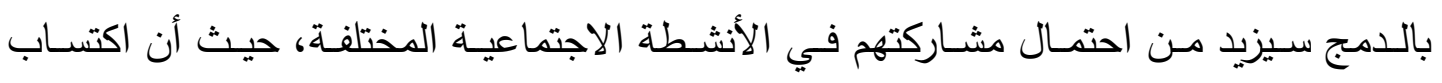

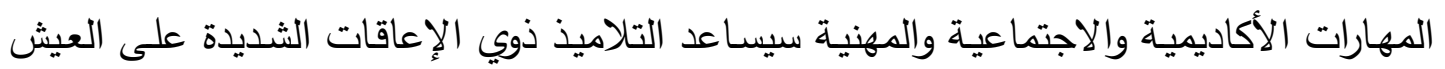
والعمل داخل المجتمع بعد مغادرة المدرسة.

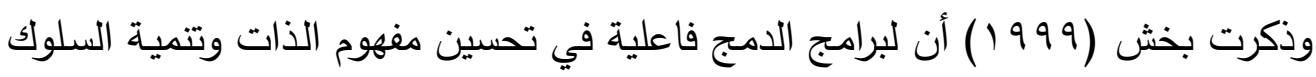

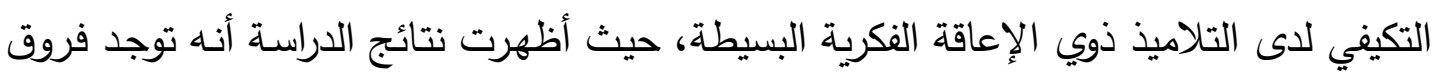

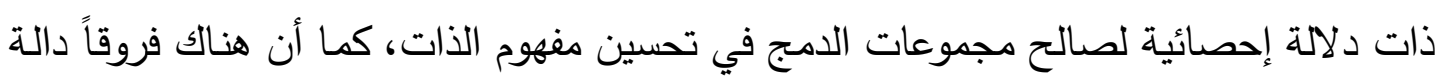

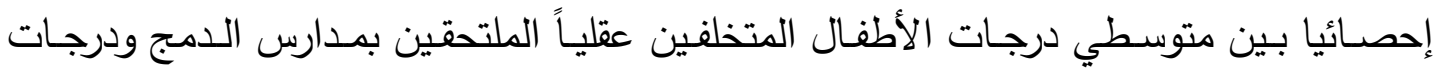

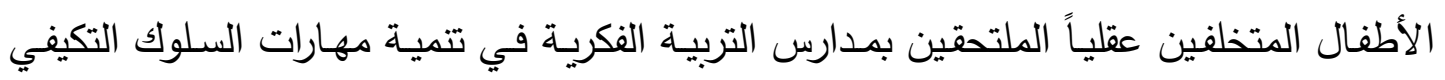
لصالح الأطفال المدمجين على أبعاد: النمو اللغوي، الأداء الوظيفي، الأعمال المنزلية، النشاط لتهبيه

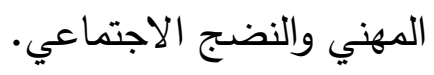


كمـا ذكر السـويدان (991) في دراستـه عن ركائز دهـج الأطفال ذوي الاحتياجـات

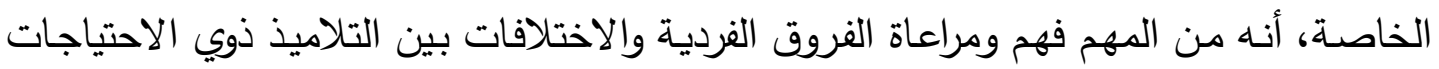

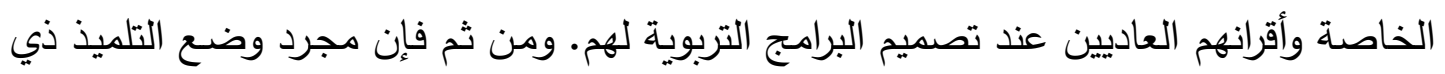

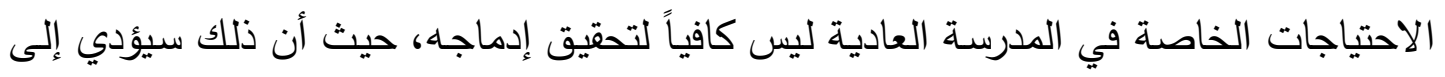

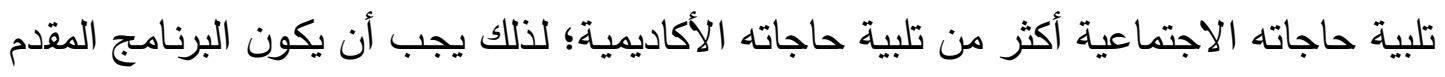

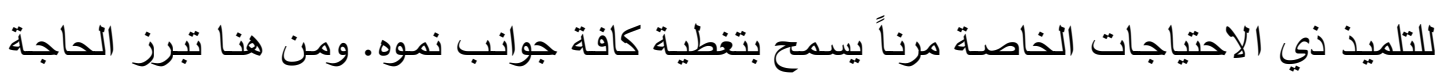

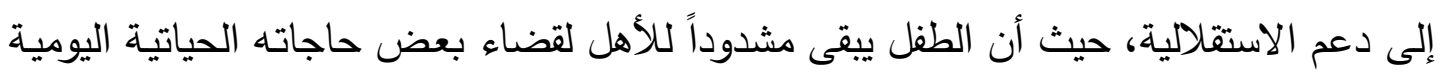

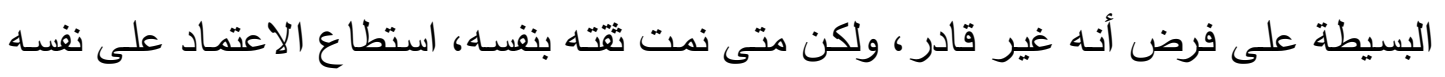

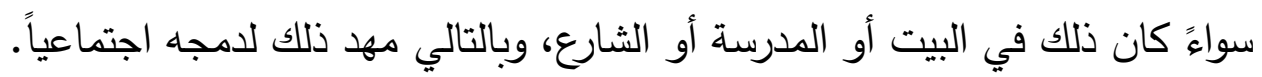

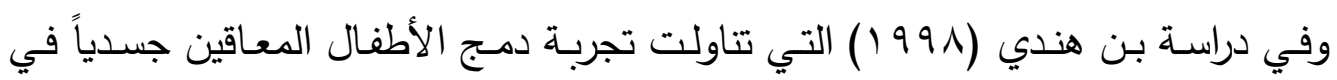

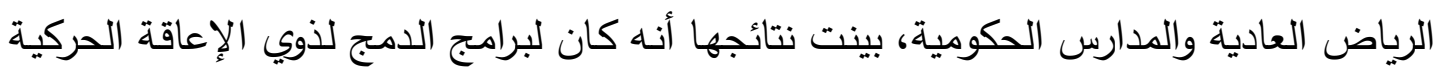

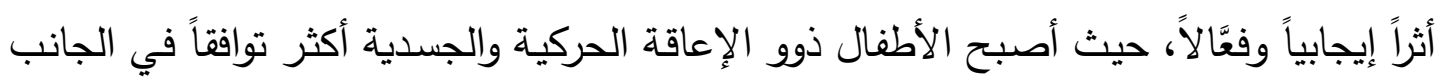

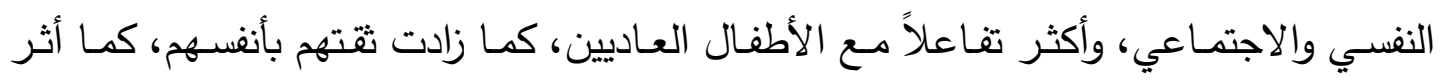

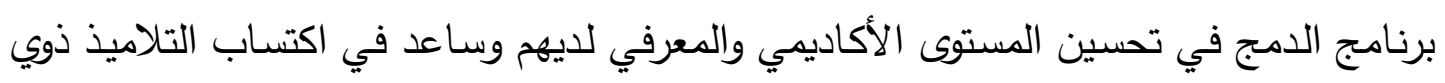
الإعاقة الجسدية أنماطاً جديدة من السلوكيات الإيجابية بتقليد أقرانهم العاديين. كما ذكر هولمز Holmes (1989) أنه يجب تعليم معظم الأطفال ذوي إعاقات التوحد

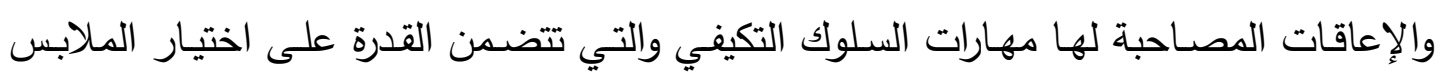

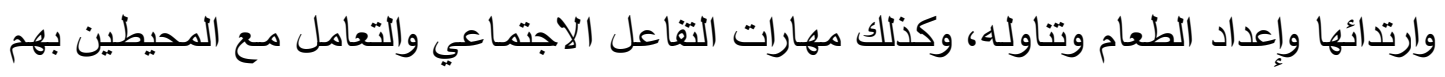

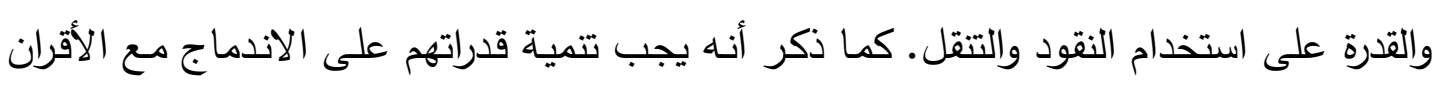

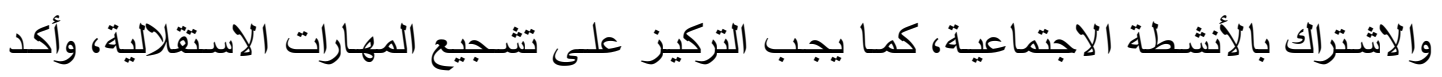
على أهمية إثباع هذا الجانب بزيادة فرص التدريب والتواصل الاجتماعي. هذا وقد أكدت نتائج العديد من الدراسات كدراسة (Lindsay,2012) ودراسة (

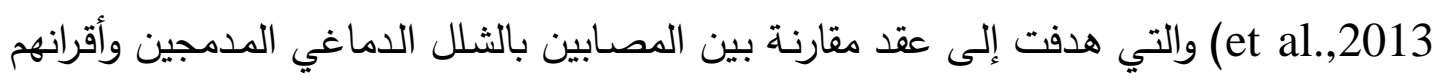
غير الدمجين في عدة متغيرات أهمها الوعي والاستقلال الذاتي والقدرة على استخدام اللغـة فئس كوسيلة للتواصل اللفظي إلى أن ذوي الثلل الدماغي المدمجين أكثر امتلاكاً لمهارة الاستقال الثيال الذاتي وأكثر قدرة على استخدام المهارات اللغوية في الحصول على احتياجاتهم الأساسية. 
كما أشارت نتائج دراسة (Ferreira et al., 2012) التي بحثت في تأثثر عملية الدمج

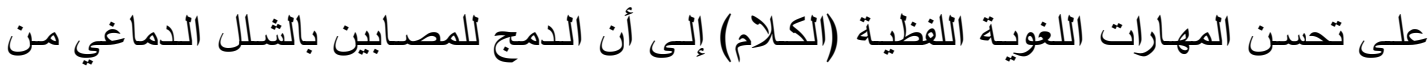
شأنه تحسين مهاراتهم اللغوية / اللفظية.

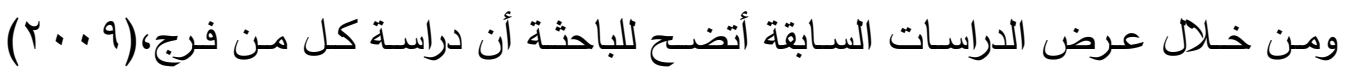

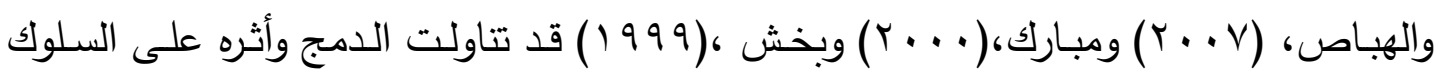
التكيفي ولكن عند ذوى الإعاقة الفكرية فقط، واهتمت دراسة ويلدر wilder (2008) بالتعرف على سلوك ذوى الإعاقات الثديدة ولكنها لم تتطرق إلى الدمج، في حين اهتمت دراسة كل من:

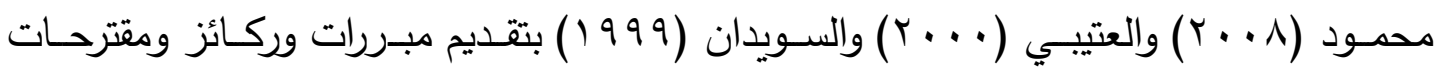

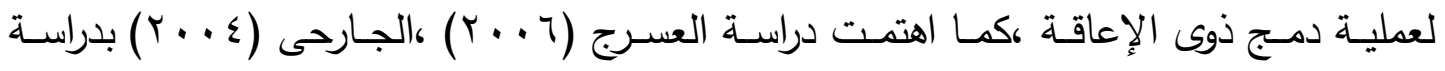
تعديل سلوك الأشخاص ذوى الإعاقة وأثره على السلوك التكيفي ولم تتطرق إلي الدمج،أما دراسة بن هندي (991 (191) فقد تتاولت الدمج لدى ذوى الإعاقة الجسدية في حين ركزت دراسة ستانكو

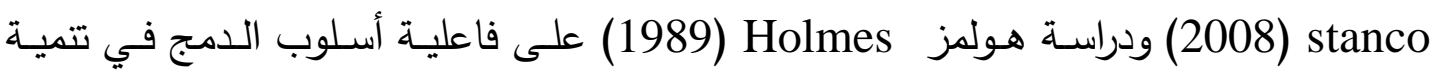
السلوك التكيفي للى متعددي الإعاقة والطفل ذو التوحد، وتأكدت الباحثة من ندرة الدراسات

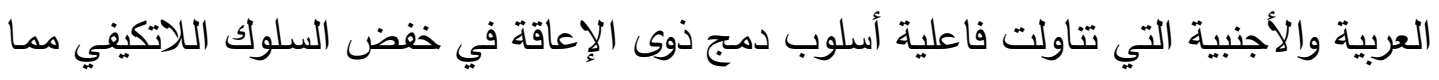
يدعو إلى أهمية هذه الدراسة في مجال التربية الخاصة وضرورة الاهتمام بفئة متعددي الاعاقة.

$$
\text { فـــروض الـدراســـة }
$$

1- يوجد فرق دال إحصائياً بين متوسط درجات الأطفال ذوي الثلل الدماغي المصحوب

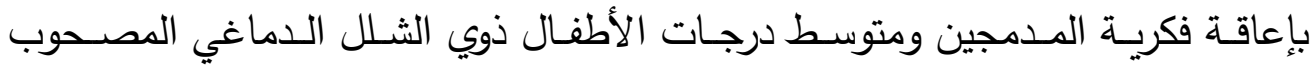

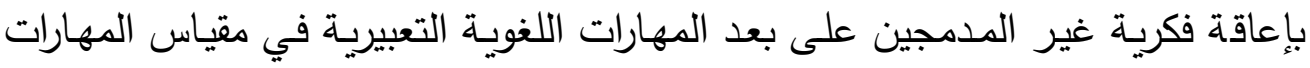

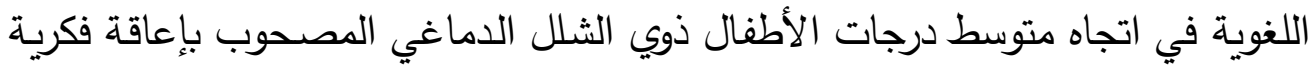
المدمجين.

ب- يوجد فرق دال إحصائياً بين متوسط درجات الأطفال ذوي الثلل الدماغي المصحوب

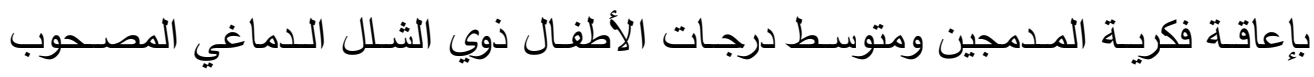

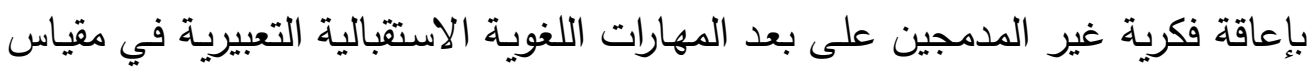


المهارات اللغويـة في اتجـاه متوسط درجـات الأطفال ذوي الشـلل الدماغي المصـحوب بإعاقة فكرية المدمجين.

$$
\begin{aligned}
& \text { الطريقة والإجراءات }
\end{aligned}
$$

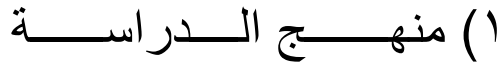

استخدمت الباحثة المـنهج الوصفي المقارن حيث قارنت بين أداء مجموعات الأطفال المدمجين ومجموعة غير المدمجين من ذوي الشلل الدماغي المصحوب بإعاقة فكرية في الأداء على مقيـاس المهـارات اللغويـة، ويعتبـر المـنهج الوصـفي المقــــن المـنهج المناسـب لطبيعـة

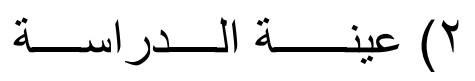

تكونت عينة الدراسة من (·r ) طفلة مصابة بالثلل الدماغي المصحوب بإعاقة فكريـة، تراوحت أعمارهم الفكرية ما بين (ع-7) سنوات وأعمارهم الزمنية (7-1) سنوات ودرجت ذكائهم تتراوح من • • إلى • V، نصفهم ملتحقات بصفوف خاصـة ضمن برنامج التربية الفكرية الملحق بالمدرسة العادية، تطبق برنامج الدمج المكاني والاجتماعي في الأنشطة اللاصفية، وتتلقى تعليماً فردياً، والنصف الآخر بمعاهد تربية فكرية غير ملحقة بمدارس عادية. وقد تم التحقق من تجانس أفراد العينة ككل من حيث العمـر الزمني، ومستوى الذكاء، والمسـتوى الاقتصـادي الاجتمـاعي للأسـرة، وبنـاءً على المعلومـات في ملفـات الأطفـال تمــ معالجة البيانات إحصائياً.

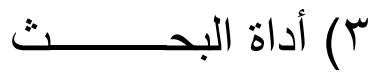
استخدمت الباحثة في هذه الدراسـة مقيـاس للمهارات اللغويـة مـن إعدادها، وقد تحققت الباحثة من الخصائص السيكومترية للمقياس من خلال حساب معاملات الصدق والثبات، حيث تم حساب الصدق باستخدام طريقة الصدق الظاهري (استخدمت الباحثة عينة استطلاعية قوامها ع r معلمـةً من معلمـات التلميذات ذوي الثـلل الدماغي المصـحوب بإعاقة فكريـة في المرحلـة الابتدائية ذوي سـابق الخبرة بالتعامل مـع هذه الفئة)، بالإضـافة إلى صـدق المحكمين (قامت الباحثـة بعرض المقيـاس على مجموعـة مـن الأسـاتذة المتخصصين في علم النفس والتربيـة الخاصـة وطلبت منهم مـا يلي: تحديد مدى انتماء / عدم انتماء البنود التي يتضمنها المقياس إلى الأبعـاد المتعلقـة بالمقيـاس، إضـافة أي بنـد يـرون إضـافته أو حذف أي بنـد يـرون ضـرورة حذفه، إعادة صياغة البنود بطريقة يسهل فهمها بحيث تصبح أكثر وضوحًا وقدرة على قياس 
ما وُضعت لقياسه. وبِناءً على نسبة الاتفاق بين المحكمين لكل بند من بنود المقياس تم الإبقاء

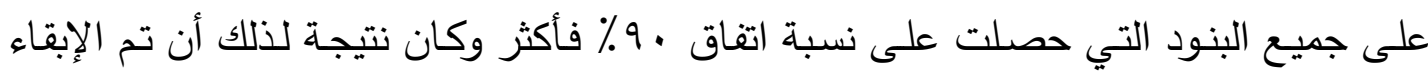

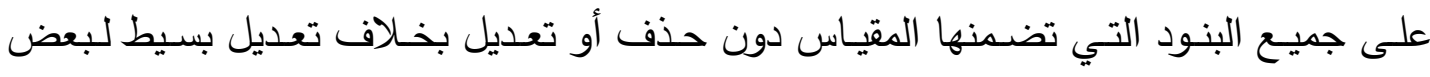

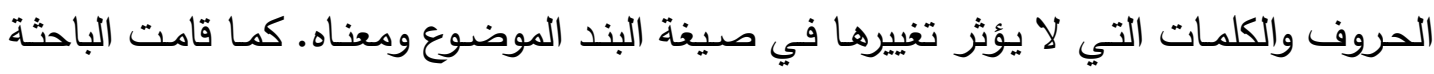

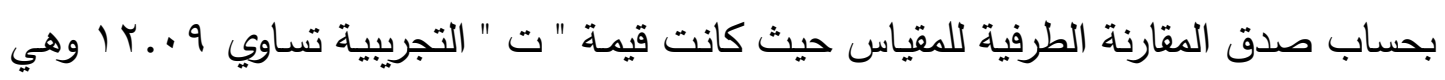

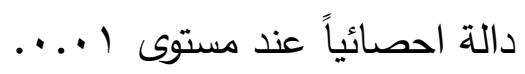

أمسا بالنسبة لثبات المقياس فقد استخدمت الباحث طريقة التجزئة النصفية وكان معامل ثبات المقياس يساوي V09. . . وهو دال احصائياً، بالإضـافة إلى طريقة إعادة التطبيق بفاصل

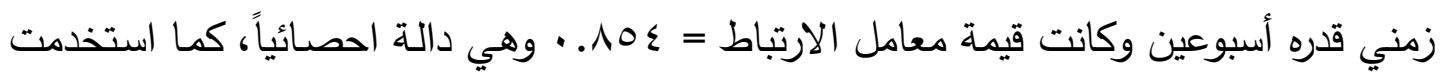

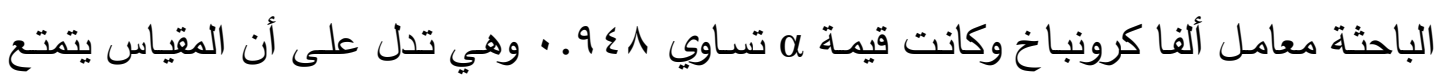

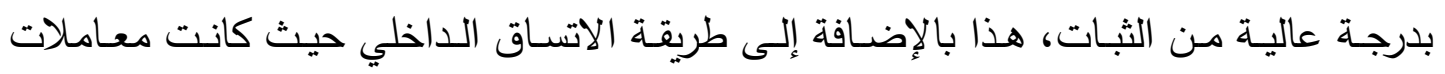

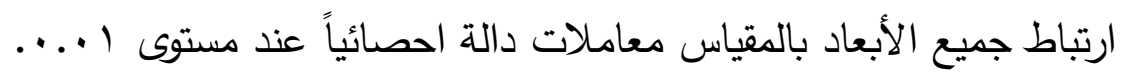

نص الفرض الأول للاراسـة على: يوجد فرق دال إحصائياً بين متوسط درجات الأطفال

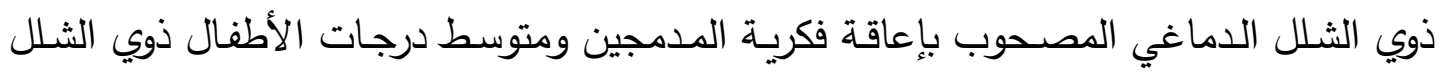

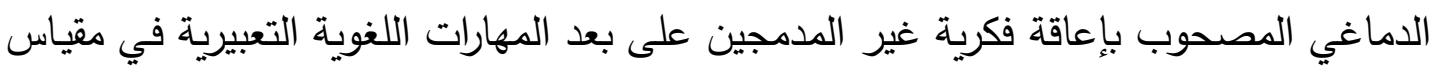

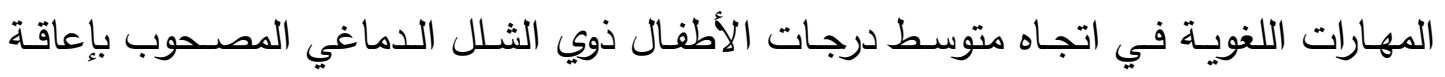
فكرية المدمجين.

Wilcoxon Test وللتحقق من صحة هذا الفرض تم استخدام اختبار ويلكوكسون للكثف عن دلالمة الفرق بين المجموعتين، وقد جاءت النتائج كما هي موضحة في الجدول التالي: - n

جدول (1)

نتائج اختبار ويلكوكسون لمتوسط درجات الأطفال ذوب الثنلل الدماغي المصحوب بإعاعاقة

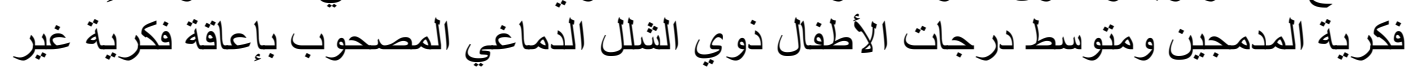

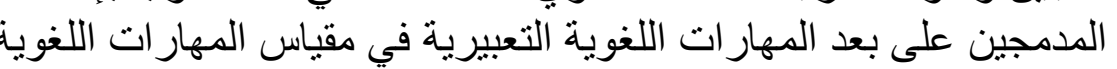

\begin{tabular}{|c|c|c|c|c|c|c|}
\hline الدلالة & قيمة Z & $\varepsilon$ & 5 & ن ن & المجمو عة & القياس \\
\hline..+1 & Y.A $\varepsilon-$ & $\varepsilon . \varepsilon$ & $\varepsilon r . V$ & 1. & المدمجين & المهــــارات اللغويــــة \\
\hline
\end{tabular}




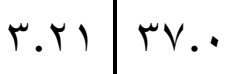 \\ 1 .

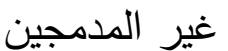 \\ التعبيرية}

يتضـح من الجدول السابق وجود فرق ذوو دلالة إحصائية بين متوسطي رتب درجات

الأطفال ذوي الثلل الدماغي المصحوب بإعاقة فكريـة المدمجين ومتوسط رتب درجات الأطفال ذوي الثلل الدماغي المصحوب بإعاقة فكريـة غير المدمجين في بعد المهارات اللغويـة التعبيريـة في مقياس المهارات اللغويـة حيث كانت قيمة Z تساوي ؟ ؟. وهي دالة إحصائيًا عند مستوى

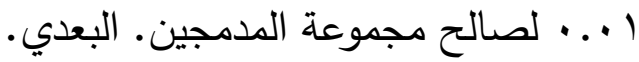

نــ الفـرض الثـاني للاراسـة علـى : يوجد فرق دال إحصـائياً بين متوسط درجـات الأطفال ذوي الشلل الدماغي المصحوب بإعاقة فكريـة المدمجين ومتوسط درجات الأطفال ذوي الشلل الدماغي المصحوب بإعاقة فكريـة غير المدمجين على بعد المهارات اللغويـة الاستقبالية في مقياس المهارات اللغويـة في اتجاه متوسط درجات الأطفال ذوي الثلل الدماغي المصحوب بإعاقة فكرية المدمجين.

وللتحقق من صـة هذا الفرض تم استخدام اختبار ويلكوكسون Wilcoxon Test للكثف عن دلالـة الفرق بين المجموعتين، وقد جاءت النتائج كما هي موضحة في الجدول التالى :

\section{جدول (r) (r) (1)}

نتائج اختبار ويلكوكسون لمتوسط درجات الأطفال ذوي الثنلل الدماغي المصحوب بإعاقة

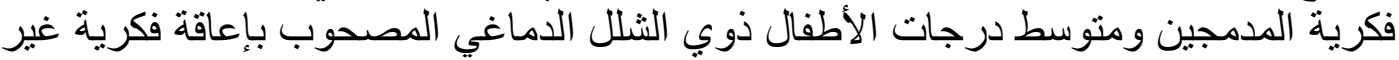
المدمجين على بعد المهار ات اللغوية الاستقبالية في مقياس المهار ات اللغية اللغوية

\begin{tabular}{|c|c|c|c|c|c|c|}
\hline الدلالة & قيمة Z & $\varepsilon$ & כ & ن & المجمو عة & القياس \\
\hline \multirow[t]{2}{*}{$\cdot . \cdot 1$} & - & T.10 & $\leqslant \varepsilon .7$ & 1 . & المدمجين & \multirow{2}{*}{ الاستهـــــارات اللغويـــــة } \\
\hline & Y.OY & $\varepsilon .+r$ & r9.0 & 1. & غير المدمجين & \\
\hline
\end{tabular}

يتضـح من الجدول السـابق وجود فرق ذوو دلالة إحصائية بين متوسطي رتب درجات الأطفال ذوي الشلل الدماغي المصحوب بإعاقة فكريـة المدمجين ومتوسط رتب درجات الأطفال ذوي الثلل الدماغي المصحوب بإعاقة فكرية غير المدمجين في بعـد المهـارات اللغويــة الاستقبالية في مقياس المهارات اللغويـة حيث كانت قيمة Z تساوي ror. r. وهي دالة إحصـئيًا عند مستوى ا +. . . لصالح مجموعة المدمجين. البعدي. 
استهدفت الدراسة الحالية التحقق من وجود علاقة بين دمج الأطفال ذوو الثلل الدماغي المصـحوب بالإعاقـة الفكريـة وقدرتهم في المهارات اللغويـة التعبيريـة وكذلك الإستقبالية، وقد توصلت النتائج الى ان الأطفال ذوي الثـلل الدماغي المصـحوب بالإعاقة الفكريـة المدمجين يتمتعـون بمستويات أعلى في المهارات اللغويـة الاستقبالية والتعبيريـة مقارنــة بنظرائهم غيـر المدمجين وهذه النتائج تتقق مع العديد من نتائج الدراسات السابقة ذات الصلة بالدراسة الحالية

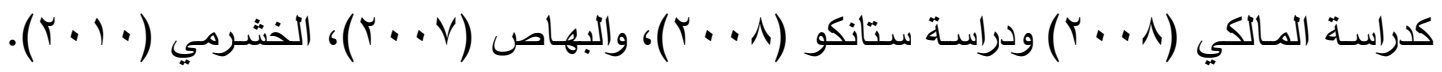
ويمكن تفسير ذلك في ضـوء أن الـمجج مـن شـأنه إكسـاب ذوي الإعاقـة عمومـاً وذوي الثـلل

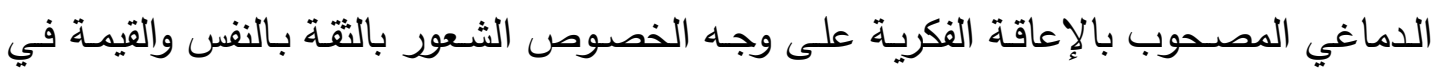

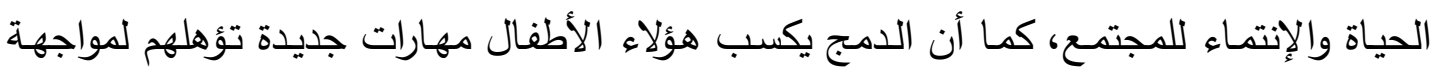

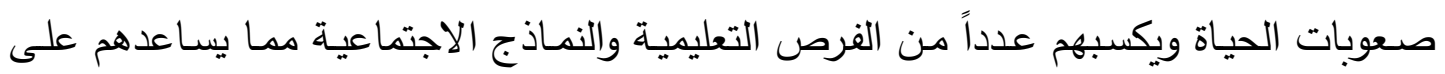

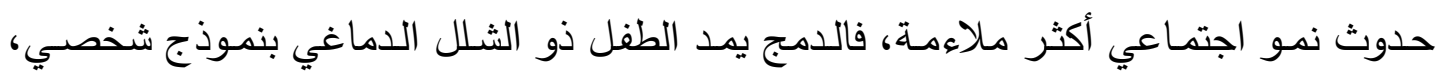

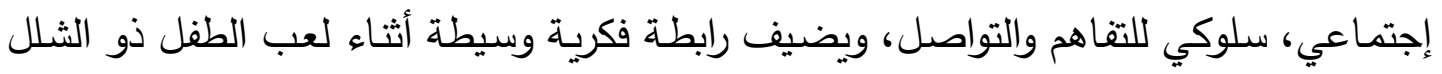

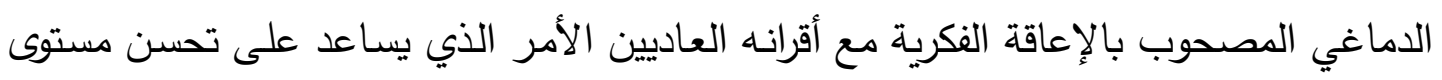
المهارات اللغوية الاستقبالية والتعبيرية. كما أن العمل مـع الطفل ذو الثـل الدماغي المصـحوب بالإعاقـة الفكريـة وفق نظـام الدمج يعتبر فرصة للطفل وللمعلم لزيادة الخبرات التعليمية الثخصية، حيث أنه يتيح الفرصـة

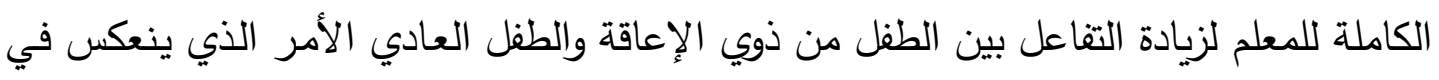
النهاية على مستوى النمو النفسي والاجتماعي والوجداني والجسمي للطفل المعاق.

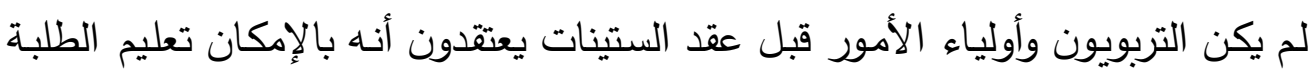

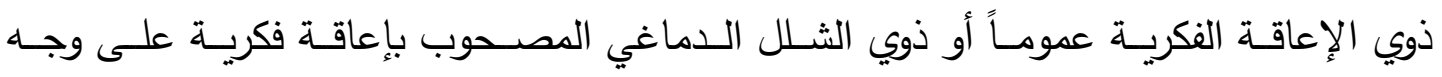
الخصوص إلا في مؤسسات ومدارس خاصة مفصولة عن الدارس العادية فالاعتقاد السائد كان أن دمج هؤلاء الطلبة في الصفوف العادية شيء غير واقعي وغير قابل للتنفيذ، ولكن الدراسات العلمية التي أجريت منذ بداية عقد الستينات بينت أن أداء الطلبة ذوي الإعاقة الفكرية عموماً 
الذين يتلقون تعلمهم في أوضاع تربوية مدمجة أفضل من أداء الطلبة الذين يتلقون تعلمهم في

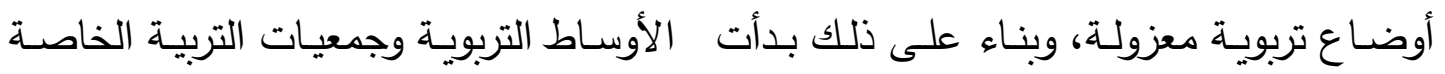
وجمعيات أولياء الأمور تتادي بإعادة النظر في الممارسات التربوية مع هذه الفئة من الطلبة داعية إلى التحول من التعليم المفصول المعزول إلى التعليم المدمج في أوضاع تربوية طبية فيعية،

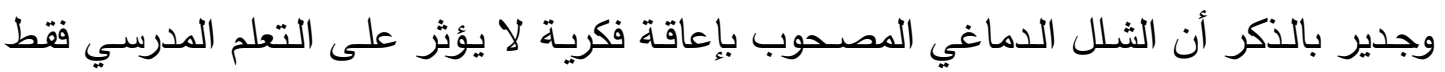

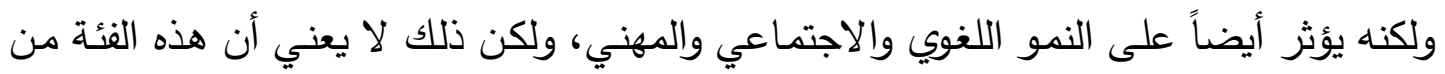

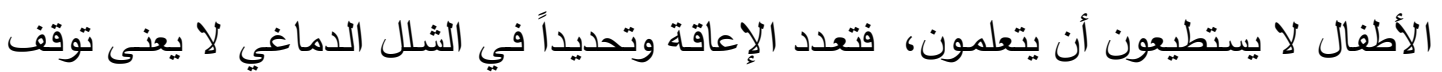

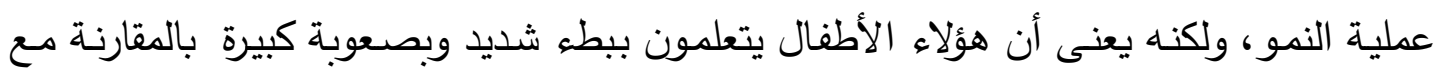

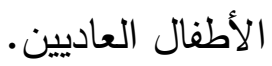

إن لكل إنسان الحق في التعليم واثبات وجوده ليكون فردا ناشطا مؤثرا كان أم متأثرا والتربية كما عرفت بأنها الإعداد للحياة، أي انك تعد وتنني جيل المستقبل وأي خلل ينتج هو نتاج جهود ربما لم تتضافر للوصول إلي الغاية التي ننشد ونتنىى وبذلك يكون لزاما علي

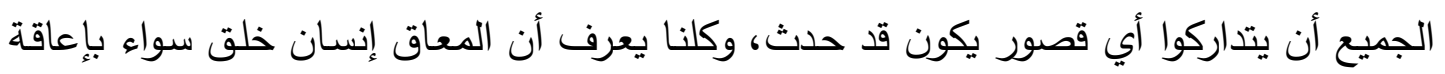

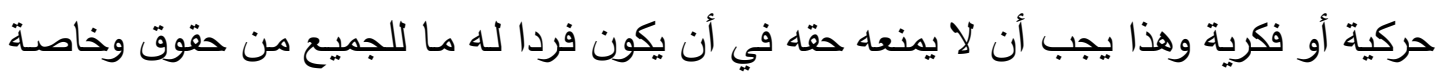

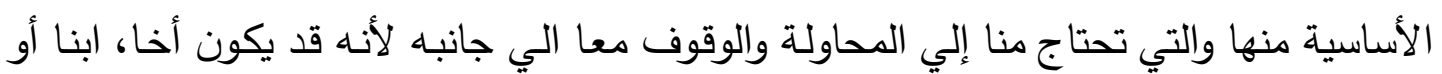

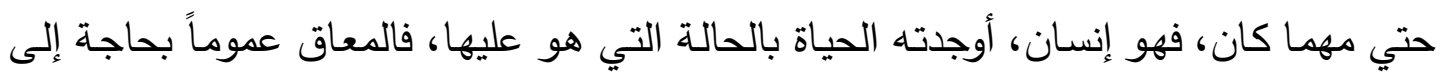
المكانة أكثر من المكان، إنه بحاجة لمزيد من الفرص والقليل من العقبات. ومن هنا جاء مفهوم ما يسمي بالدمج، والذي يعني تعليم المعاقين في المدارس العادية مع أقرانهم العاديين وإعدادهم للعمل في المجتمع، والدمج هو احد الاتجاهات الحديثة في التربية

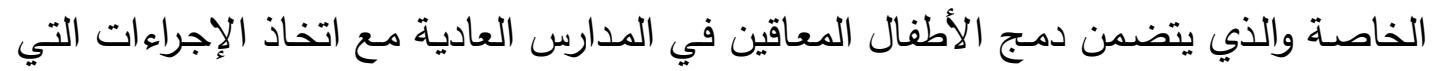
تتضمن استفادتهم من البرامج التربوية في هذه المدارس، مع ضرورة أن يقضي هؤلاء الأطفال

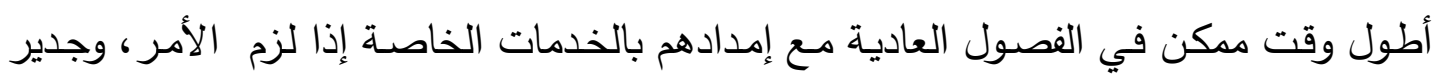

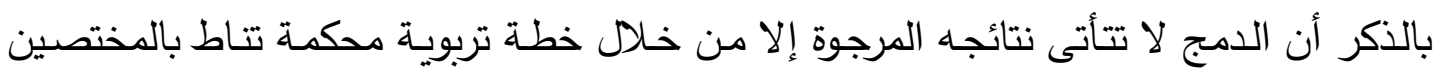

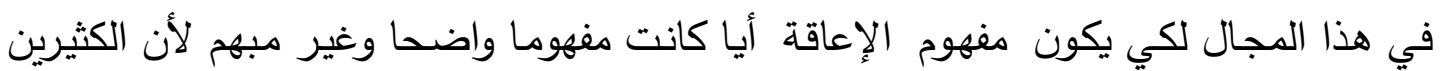


وخاصة من هم في أعمار صغيرة ينظرون للمعاق علي انه مخلوق من كوكب آخر وجوده فقط

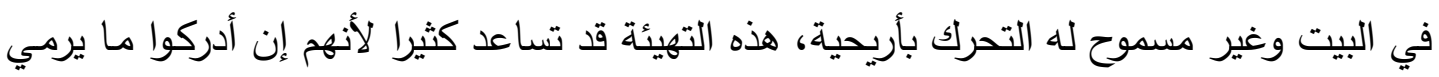
إليه هذا الأمر فأنهم سوف يساعدون أقرانهم المعاقين و سيساهم في كسر الحواجز بين المفاهيم

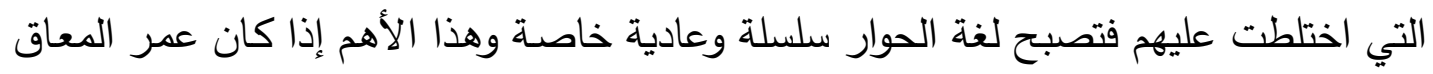

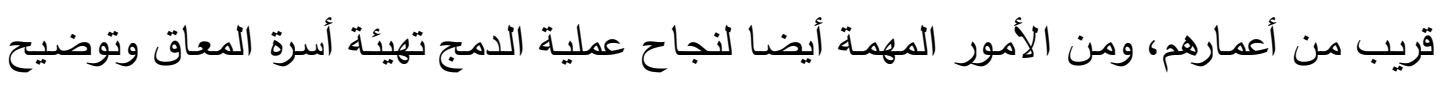

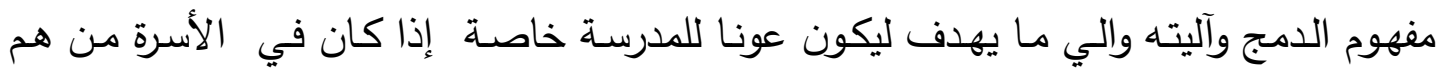
قريبون من عمر المعاق لأنها حتما عملية متكاملة، إن عدم تفهم الأسرة للإعاقة وتقبلها سيكون

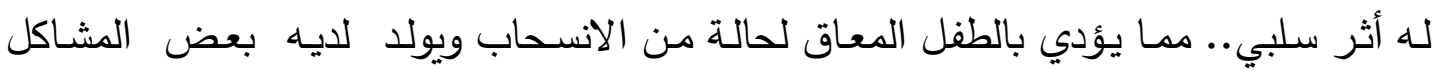
السلوكية والنفسية والاجتماعية.

\section{توصيـات الــدر/ســة}

بناء على النتائج التي توصلت إليها الدراسة , وفي ضوه ما توصلت إليه الباحثة من تحليل وتقسير لهذه النتائج , تقترح الباحثة مجموعة من التوصيات:

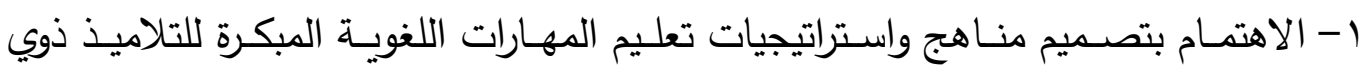
الشلل الدماغي المصحوب بإعاقة فكرية.

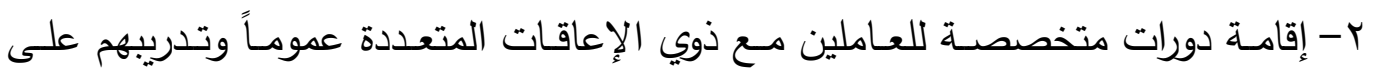
استخدام أحدث البرامج المستخدمة في التعامل معهم, ويشمل ذلك البرامج العلاجيـة والتدريبية والسلوكية.

r- الاهتمام بإضافة خدمات مصاحبة على قدر عالٍ من الكفاءة في المراكز المتخصصة في مجال الإعاقة مثل: أخصائي التخاطب, وأخصائي العلاج الطبيعي, ومعلم التربية البدينة. ع - الاهتمام بدراسة موضوع تتمية المهارات اللغوية للطفل ذو الإعاقة بوجه عام. ه- التمهيد الجيد لعملية الدمج القائم على بحوث ودراسات تجرى على واقع هؤلاء التلاميذ والأطفال حتى يمكن حل مشكلاتهم وتلبية احتياجاتهم في ضوء خصائصهم وسماتهم. 


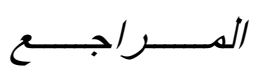

أبو العزايم، محمد إسماعيل (7 91 ( ). الضعف في القراءة تشخيصسه و علاجه. القاهرة: عالم الكتب.

بخش، أميرة طـه (999 (99). فاعليـة أسـلوب الـدمج على مفهوم الذات والسلوك التكيفي لـدى

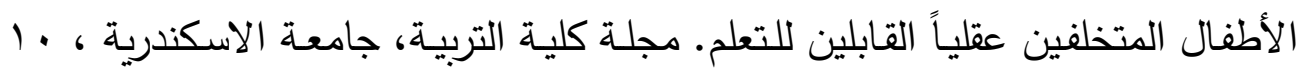

$$
.499-40 \leqslant 6(1)
$$

بن هندي، منيرة عيسى (991 ( ). تجربـة دمـج الأطفال المعـين جسدياً في الريـاض العاديـة والمدارس الحكوميـة. ندوة دمج الأشخاص ذوي الاحتياجات الخاصسة في دول مجلس

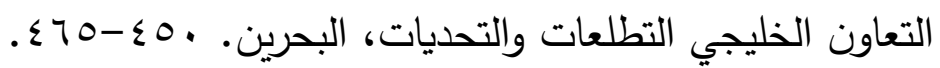

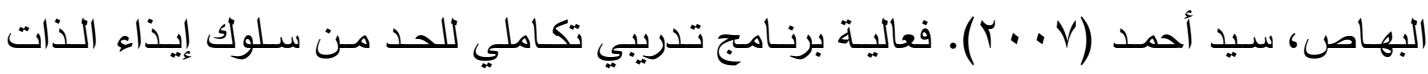
وتحسـين التفـاعلات الاجتماعيـة لـدى الأطفـال المتخلفين عقليـاً. مجلـة كليـة التربيـة

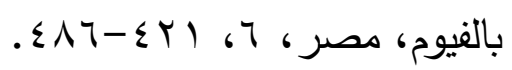

جـاب الله، علـي سـعد. حـافظ، وحيد السيد. عبدالباري، مـاهر شـعبان (9 . . ب). تعليم اللغـة العربية لذوي الإعاقة. القاهرة: إيتراك للطباعة والنشر والتوزيع.

الجارحي، سيد جارحي السيد يوسف (ع r). فاعلية برنامج تدريبي في تنمية بعض مهارات السلوك التكيفي لاى الأطفال التوحديين وخفض سلوكياتهم المضطربة. رسالة ماجستير غير منشورة، كلية التربية، جامعة عين شمس. جعفر، غسان (1 ( . ץ). التخلف العقلي عند الأطفال. بيروت: دار الحرف العربي.

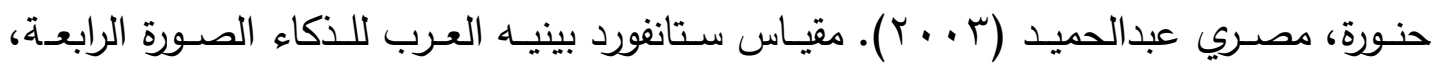
القاهرة: مكتبة الأنجلو المصرية.

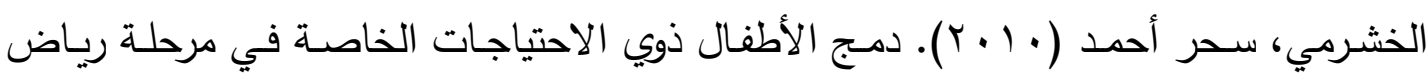

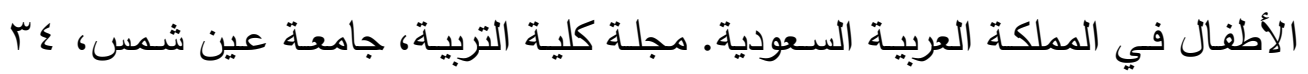
. $\varepsilon r V-\varepsilon \cdot r \cdot(1)$

الخطيب، جمال (T · . ץ). مقدمة في الإعاقة الجسمية والصحية. عمان: دار الشروق.

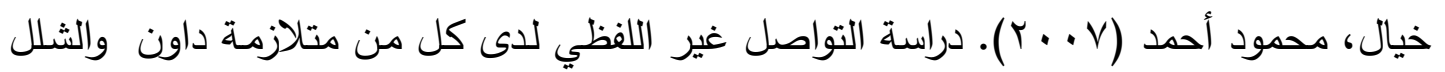
الـماغي والذاتويـة مدـن يعـانون مـن الإعاقـة العقليـة. المؤتمر الإقليمي لعلم الـفس، رابطة الاختصاصيين المصريين، القاهرة: 099-0Y 9 .0Y. 
السرطاوي، عبدالعزيز ـ الصمادي، جميل (• ( +ץ). الإعاقات الجسمية والصحية، الأردن: دار الفكر العربي.

السويدان، حامد دخيل (1991(1). ركائز دمج الأطفال ذوي الاحتياجات الخاصـة في المدارس

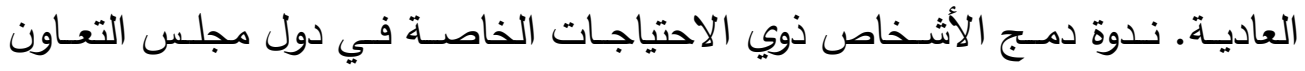

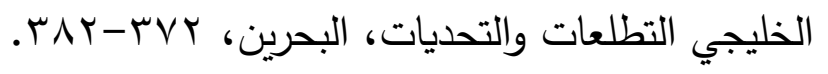

صادق، فاروق (910 (1). مقياس السلوك التكيفي، القاهرة: الأنجلو المصرية.

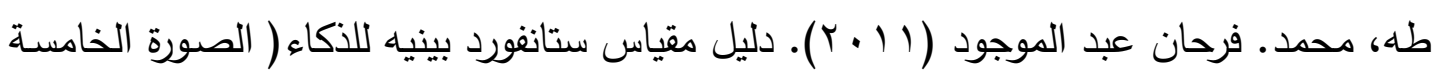
)، القاهرة: المؤسسة العربية لإعداد وتقنين ونشر الاختبارات النفسية.

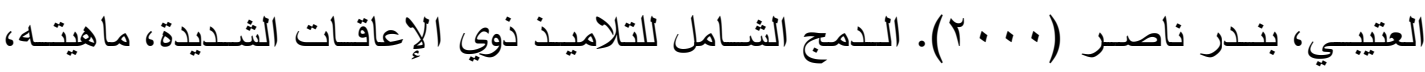

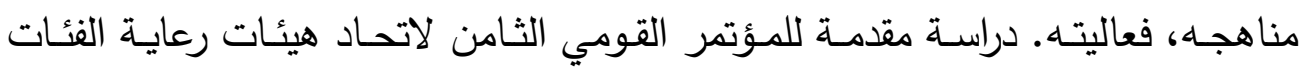
الخاصة والمعوقين بجمهورية مصر العربية.

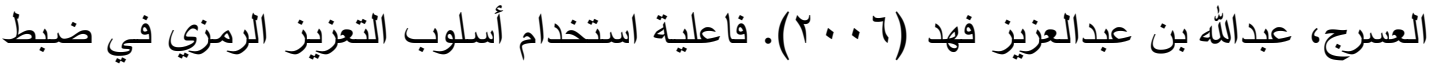
المشكلات السـلوكية لـدى ذوي متلازمـة داون في جمعيـة النهضــة النسـائية الخيريـة بالرياض. جامعة نايف العربية للعلوم الأمنية، الرياض.

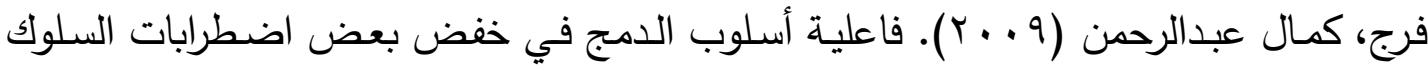

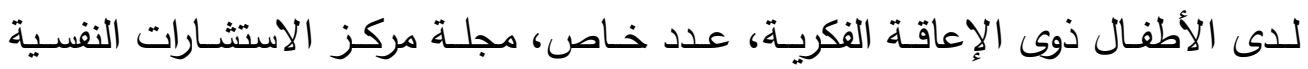
والتربوية،كلية الآداب جامعة المنوفية.

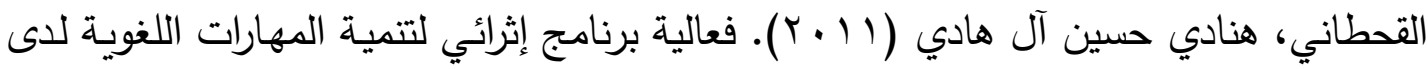
الأطفال ذوي الإعاقة الفكرية. رسالة دكتوراه، جامعة عين شمس، القاهرة.

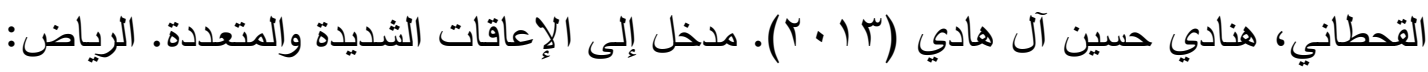

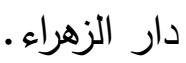

القحطاني، هنادي حسين آل هادي (؟ ا ـ ب). المهارات اللغوية لذوي الإعاقة الفكرية. الرياض:

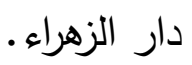

القريوتي، يوسف. السرطاوي، جمال. الصمادي، جميل (r ( + ب). الدذخل إلى التربية الخاصة.

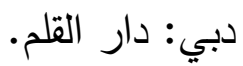


المالكي، حسين بن علي (1 · ب). مهارات السلوك التكيفي عند تلاميذ معاهد وبرامج التربية

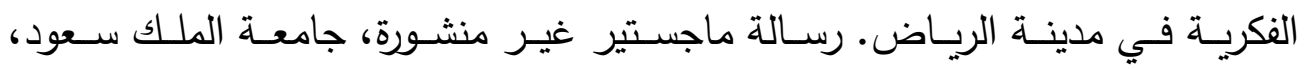
الرياض.

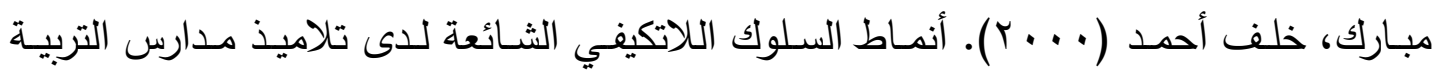

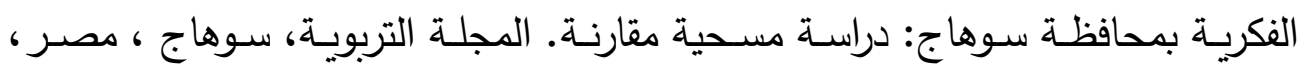

$$
\text { } 1 \text { (يناير) . }
$$

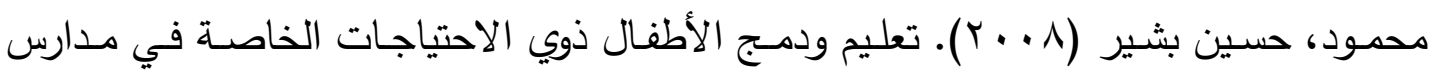

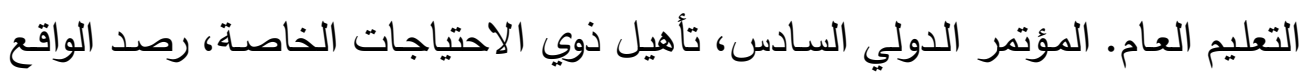

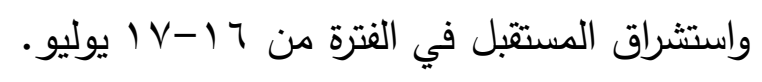

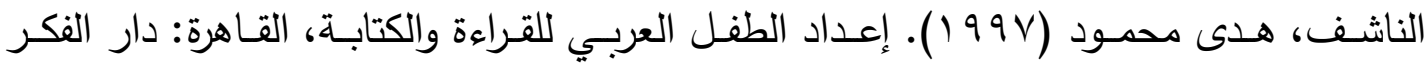

$$
\text { العربي. }
$$

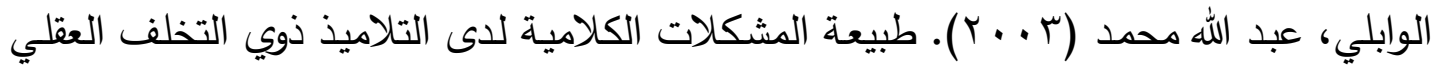

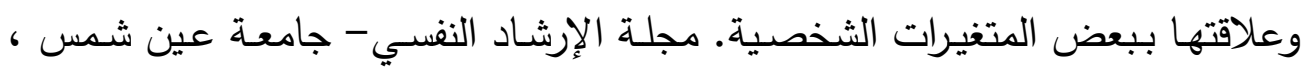

$$
\text { .9r-or ، (11) } 17
$$

Conners, Frances A. Rosenquist, celia, J; Sligh, Allison, C; Atwell, Julie, A\& Kiser, Tanya(2006). Phonological Reading Skills Acquisition by Children with Mental Retardation. Journal of developmental Disabilities, 27, 2, 121-137

Dutt, Anuradha \& Salil, Kumar. (2010). The Effects of Skill Training on Preference for Individuals with Severe to Profound Multiple Disabilities. Unpobished Doctoral Dissertation. The University of Iowa.

Ferreira,A.;Ariane,O.\&Ferreira, S. (2012). Accessibility for People with Cerebral Palsy: The use of Blogs as an Agent of Social Inclusion. Procedia Computer Science; 14 (3), 245-253. 
Gump, w. ; Mutchnick, S. \& moriyarti, N. (2013). Selective dorsal rhizotomy for spasticity not associated with cerebral palsy: reconsideration of surgical inclusion criteria. Neurosurgical Focus [Neurosurg Focus]; Vol. 35 (5), pp. E6.

Heward. L. William. (2009). Exceptional Children, an Introduction to Special Education. Prentice Hall, 9th Ed.

Holmes, D.L.(1989). The years a head : Adults with autism . A parent's guide.

Kleinert, H: L., Miracle, S., \& Sheppard-Jones, K. (2007). Including Students with Moderate \& Sever Intellectual Disabilities in School extra curriculum \& Community recreational activities. Intellectual \& develop intellectual disabilities. 45, 46-55.

Lindsay, S. (2012). Strategies for improving disability awareness and social inclusion of children and young people with cerebral palsy. Health \& Development, Nov; 38 (6) , 809-16

Mirjana, Japundza-Milisavljevic; Aleksandra, Djuric-Zdravkovic, \& Dragana, Macesic-Petrovic. (2010). The socially acceptable behavioral patterns in children with intellectual disabilities. Procedia - Social and Behavioral Sciences. V 5, 37-40.

Reeder, Angie. S. (2002). Long Latency Audiotory Evoked Potentials and Behavior State Conditions Among Children with Severe, Multiple Disabilities. Unpublished Doctoral Dissertation. University of Kansas. 
د / هنادي حسين آل هادي القحطاني مستوى المهارات اللغوية لدى الإطفال المصابين بالثلل الدماغي المصحوب بإعاقة فكرية

Singh, Nirbhay N. Lancioni, Giulio, E. Winton, Alan S. W. Wahler, Robert, G. Singh, Judy \& Sage, Monica. (2004). Mindful Caregiving Increases Happiness among Individuals with Profound Multiple Disabilities. Research in Developmental Disabilities, 25, 207-218.

Stanco, Doreen, Frances (2008). The efficacy of a vocational program on improving social interactions in adolescents with multiple disabilities, autism, \& cognitive impairments. . Unpublished THESIS William Paterson University of New Jersey. NJ.

Talbott. Suzette z.(2010). perceptions of health-related quality of life, teasing, and school connectedness in students with disabilities. Unpublished doctoral dissertation. Azusa pacific university. California.

Van, K. P. ; Bos, H. Nakken, P. G. Nicolay \& E. J. Van Houten (2007). Adults with mild intellectual disabilities: can their reading comprehension ability be improved?. Journal of intellectual disability research. 51, 11, 835-849.

Wilder, Jenny. (2008). Proximal Processes of Children with Profound Multiple Disabilities. Unpublished Doctoral Dissertation. Stockholm University Sweden 